\title{
Dalangtan Saline Playa in a Hyperarid Region of Tibet Plateau-III: Correlated Multiscale Surface Mineralogy and Geochemistry Survey
}

\author{
Pablo Sobron, ${ }^{1,2}$ Alian Wang, ${ }^{3}$ David P. Mayer, Jennifer Bentz, Fanjing Kong, and Mianping Zheng ${ }^{6}$
}

\begin{abstract}
We report the first multiscale, systematic field-based testing of correlations between orbital scale advanced spaceborne thermal emission and reflection radiometer visible near-infrared (VNIR)/shortwave infrared (SWIR) reflectance and thermal infrared relative emissivity and outcrop scale Raman spectroscopy, VNIR reflectance, $\mathrm{X}$-ray diffraction (XRD), and laser-induced breakdown spectroscopy (LIBS) mineralogy and chemistry in a saline dry lakebed. This article is one of three reports describing the evolution of salt deposits, meteorological record, and surface and subsurface salt mineralogy in Dalangtan, Qaidam Basin, a hyperarid region of the Tibet Plateau, China, as potential environmental, mineralogical, and biogeochemical analogues to Mars. We have successfully bridged remote sensing data to fine scale mineralogy and chemistry data. We have defined spectral end-members in the northwestern Qaidam Basin and classified areas within the study area on the basis of their spectral similarity to the spectral end-members. Results of VNIR/SWIR classification reveal zonation of spectral units within three large anticlinal domes in the study area that can be correlated between the three structures. Laboratory Raman, VNIR reflectance, XRD, and LIBS data of surface mineral samples collected along a traverse over Xiaoliangshan (XLS) indicate that the surface is dominated by gypsum, Mg sulfates, $\mathrm{Na}$ sulfates, halite, and carbonates, with minor concentrations of illite present in most samples as well. Our results can be used as a first step toward better characterizing the potential of orbital reflectance spectroscopy as a method for mineral detection and quantification in salt-rich planetary environments, with the benefit that this technique can be validated on the ground using instruments onboard rovers. Key Words: HyperaridSpectroscopy-Mars—Remote sensing-Multiscale mineralogical and geochemical survey. Astrobiology 18, $\mathrm{xxx}-\mathrm{xxx}$.
\end{abstract}

\section{Introduction}

N SITU InSTRUmEnTs on Mars landers and rovers have enabled unprecedented fine scale investigations of the mineralogy (Klingelhöfer et al., 2003; Christensen et al., 2004; Blake et al., 2012), chemistry/geochemistry (Toulmin et al., 1977; Rieder et al., 2003; Kounaves et al., 2010; Wiens et al., 2012), rock/regolith textures (Edgett et al., 2012; Bell et al., 2013), and organic carbon (Summons et al., 2013). The upcoming NASA Mars 2020 (Williford, 2018) and ESA ExoMars Rover (Vago et al., 2006) missions will fly instruments that will provide ground-breaking in situ sensing capabilities and facilitate more detailed fine scale detection and analysis of chemical elements, minerals, and organic compounds than ever before.

Orbital (spaceborne) remote sensing offers the best platform to both efficiently and effectively characterize Mars surface features across a range of spatial and temporal

\footnotetext{
${ }^{1}$ SETI Institute, Mountain View, California.

${ }^{2}$ Impossible Sensing, St. Louis, Missouri.

${ }^{3}$ Department of Earth and Planetary Sciences and McDonnell Center for Space Sciences, Washington University in St. Louis, St. Louis, Missouri.

${ }^{4}$ US Geological Survey, Astrogeology Science Center, Flagstaff, Arizona.

${ }^{5}$ Department of Geological Sciences and Geological Engineering, Queen's University, Kingston, Canada.

${ }^{6}$ Institute of Mineral Resources, Chinese Academy of Geological Sciences, Key Lab of Saline Lake Resources and Enviornments, Ministry of Lands and Resources, Beijing, China.
} 
Table 1. Analytical Techniques Used in This Work for Field and Laboratory Analyses, and Comparable Instrumentation Currently and Soon-To-Be Deployed on Mars

\begin{tabular}{llr}
\hline Technique used in this work & \multicolumn{1}{c}{ Comparable instrument on Mars (mission) } & Launch date \\
\hline $\begin{array}{l}\text { Orbital IR reflectance spectroscopy } \\
\text { (visible near to thermal IR) }\end{array}$ & OMEGA (ESA Mars Express) & 2003 \\
Contact IR reflectance spectroscopy & CRISM (NASA MRO) & 2005 \\
$\quad$ (visible NIR) & Mini-TES (NASA MER) & 2013 \\
Raman spectroscopy (laser at 532 nm) & RLS (ESA ExoMars) & 2020 \\
& SuperCam (NASA Mars 2020) & 2020 \\
LIBS & ChemCam (NASA MSL) & 2020 \\
& SuperCam (NASA Mars 2020) & 2011 \\
X-ray powder diffraction & LIBS instrument aboard Chinese Mars rover (CNSA Mars 2020) & 2020 \\
& CheMin (NASA MSL) & 2020
\end{tabular}

IR = infrared; LIBS = laser-induced breakdown spectroscopy; MSL = Mars Science Laboratory; NIR =near-infrared.

scales. For example, orbiters currently deployed around Mars (Schmidt, 2003; Zurek and Smrekar, 2007; ISRO, 2015) generate high-resolution optical imaging (McEwen et al., 2007; Robinson et al., 2010), and hyperspectral data (Bibring et al., 2006; Murchie et al., 2007) that are used to characterize surface materials at scales that range from meters to kilometers per pixel, and to observe the temporal evolution of surface features (Ayoub et al., 2014).

Although these scales are appropriate for studying mineral distributions (Bandfield, 2002; Ehlmann et al., 2011; McGuire et al., 2013), stratigraphy (Milliken et al., 2010; Fassett et al., 2012; Noe Dobrea et al., 2012), and even context-based habitability (Brown et al., 2010; Michalski and Niles, 2010; Bishop et al., 2013), they are not suited to investigate the most diagnostic physicotextural, geochemical, and other indicators of preserved biosignatures. Such features, key for the astrobiological exploration of Mars, can only be explored through fine scale measurements with landed platforms.

There is, however, a key drawback of landed craft compared with orbiters. They have restricted (if at all) lateral mobility, which typically limits the spatial coverage to a few kilometers from the landing site. Mars orbital spacecraft provide unique measurements of geophysical and mineralogical features globally and repeatedly. Nevertheless, it is recognized that quantitative ground truth analyses are needed to assess the validity of spectral remote sensing (Baker, 2013); it is, therefore, essential to provide ground-based benchmarks and cross-calibration standards to ensure the self-consistency of information products.

Taken together, the requirements of upcoming missions to include the search for signs of life (e.g., Mars 2020 and ExoMars) and the drawbacks of both landed and orbital sensing indicate that significant advancements in Mars observation are expected to come about only by (1) implementing terrestrial analog studies to understand processes on Earth and interpret and ground truth remotely sensed data sent back from Mars and (2) developing more systematic capabilities for the fusion of in situ/ground microscale and remote/satellite macroscale data. Analog and fused data can be integrated with models, at relevant scales, to increase our ability to identify the most valuable sites for habitability and biosignature potential, characterize materials from macro- to microscale, and ultimately help return the most valuable martian samples to Earth.
There are several examples that demonstrate the importance and impact of fusing in situ measurements of properties such as spectral reflectance, fluorescence, temperature, and soil moisture with remotely sensed topography and spectral reflectance signals to create relevant multiscale models for the characterization of Mars analogues (Baldridge et al., 2004; Brown et al., 2004, 2005; WarrenRhodes et al., 2007; Seelos et al., 2010; Bishop et al., 2011; Clarke and Bourke, 2011; Hauber et al., 2011).

This article reports the first multiscale systematic field-based testing of correlations between orbital scale advanced spaceborne thermal emission and reflection radiometer (ASTER) visible near-infrared (VNIR)/SWIR reflectance and thermal infrared (TIR) relative emissivity and outcrop scale Raman spectroscopy, VNIR reflectance, X-ray diffraction (XRD), and laser-induced breakdown spectroscopy (LIBS) mineralogy and chemistry in a saline dry lakebed. This article is one of three describing the salt mineralogy and biosignatures in Dalangtan (DLT), Qaidam basin, a hyperarid region of the Tibet Plateau, China, as potential environmental, mineralogical, and biogeochemical analogues to Mars (see Kong et al., 2018 and Wang et al., 2018, this volume).

The novelty of this work is the demonstration of bridging multiscale data from an intensive study of mineral distribution using technologies currently and soon-to-be deployed on Mars (Table 1).

\section{Study Area}

The operational scale of this study is the full extent of the ASTER VNIR subset scene in Figure 1. Although we used orbital remote sensing data from the full scene, we only discuss the Xiaoliangshan (XLS) anticlinal dome in detail. This area was the site of a paleolake that existed from the Paleocene until the late Pleistocene (Fig. 2). Drill core studies indicate that this paleolake transitioned from freshwater to saline evaporitic conditions by the late Pliocene as the climate in the basin began to aridify and the lake depocenter migrated toward the southeast in response to tectonic uplift of the northwestern corner of the Qaidam Basin (Qi et al., 1993; Xia et al., 2001).

Regional deformation during the Pleistocene inferred to be caused by long-distance propagation of compressive stress associated with the Indian-Eurasian continental collision 


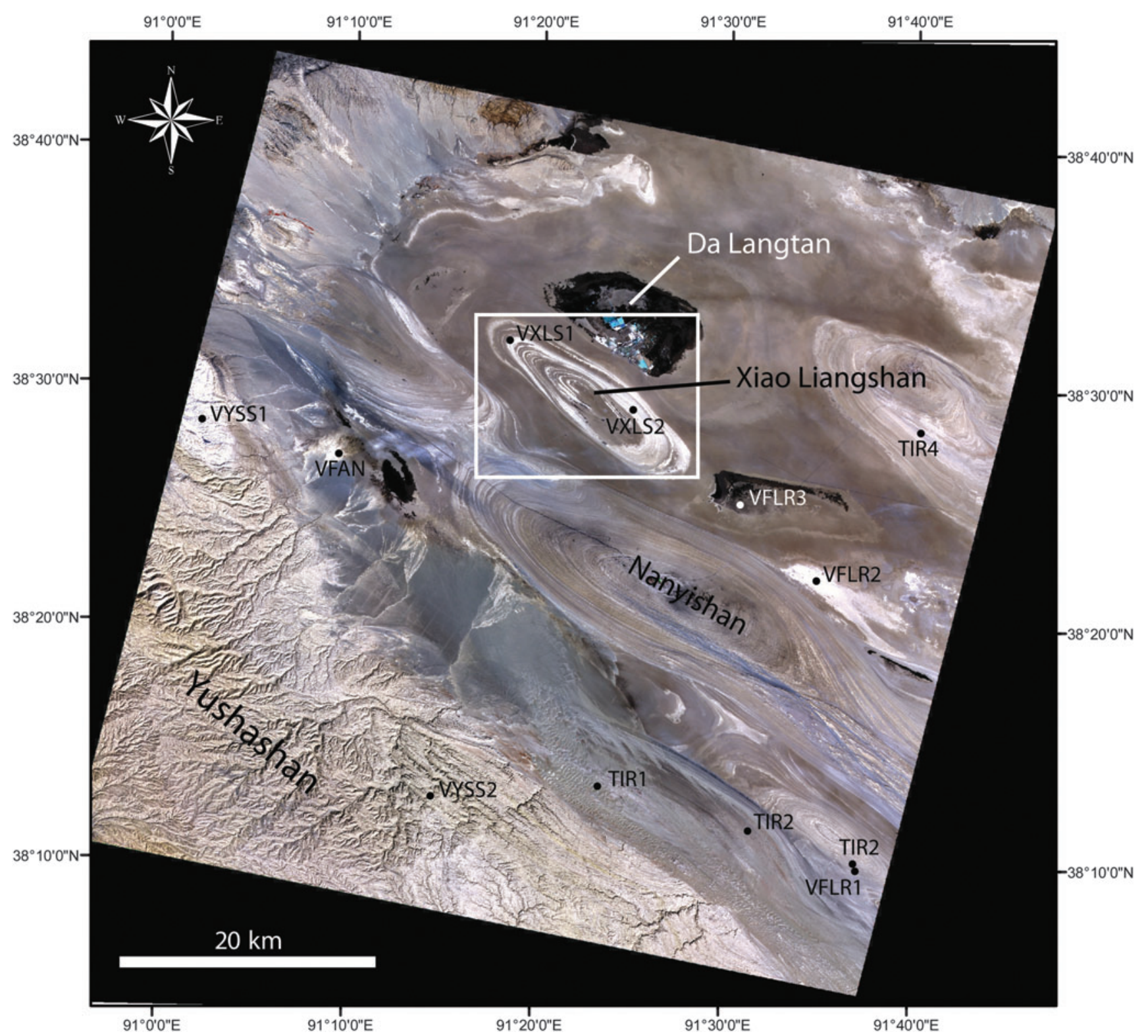

FIG. 1. Full ASTER scene shown on ASTER VNIR color image. White box shows the location of the Xiaoliangshan anticlinal dome. ASTER, advanced spaceborne thermal emission and reflection radiometer; VNIR, visible near-infrared.

created a series of northwest-southeast trending anticlinal domes throughout the basin (Xia et al., 2001; Liu et al., 2009). Because of this deformation, the existing lake basin became segmented into a series of smaller secondary basins. Lake water in the northwestern Qaidam Basin evaporated completely by the late Pleistocene, creating the modern playa surface on the floor of the basin. Virtually all identification of salt deposits and saline brines in the Qaidam Basin has come from ground-based mapping and drill core studies (see review in Zheng, 1997).

The remoteness and harsh climate of the Qaidam Basin complicate access to many areas and limit the ability of researchers to map extensive playa deposits accurately. As of July 2018, only a few remote sensing studies of the Qaidam Basin were available in the literature. These studies are mostly limited to using single band images to map the structural geology of the basin (e.g., Bailey and Anderson, 1982) and de- scribe geomorphological features (Anglés and Li, 2017; Xiao et al., 2017) or hyperspectral images over small areas to identify hydrocarbons associated with natural gas deposits (Hu et al., 2007). We are not aware of previous remote sensing studies of the surface mineralogy of the Qaidam Basin.

\section{Methods}

\subsection{Field sampling}

We collected samples from several sites along a traverse on the slope of the XLS anticlinal dome. Figure 3 is a highresolution QuickBird image showing the locations of the sampling sites along the traverse route recorded with a handheld GPS receiver. Surface materials along the traverse included blade-like efflorescences of gypsum, halite crusts, and an ubiquitous thin coating of tan to light brown-colored fine, sand-sized grains (Fig. 4). Areas on XLS that appear 


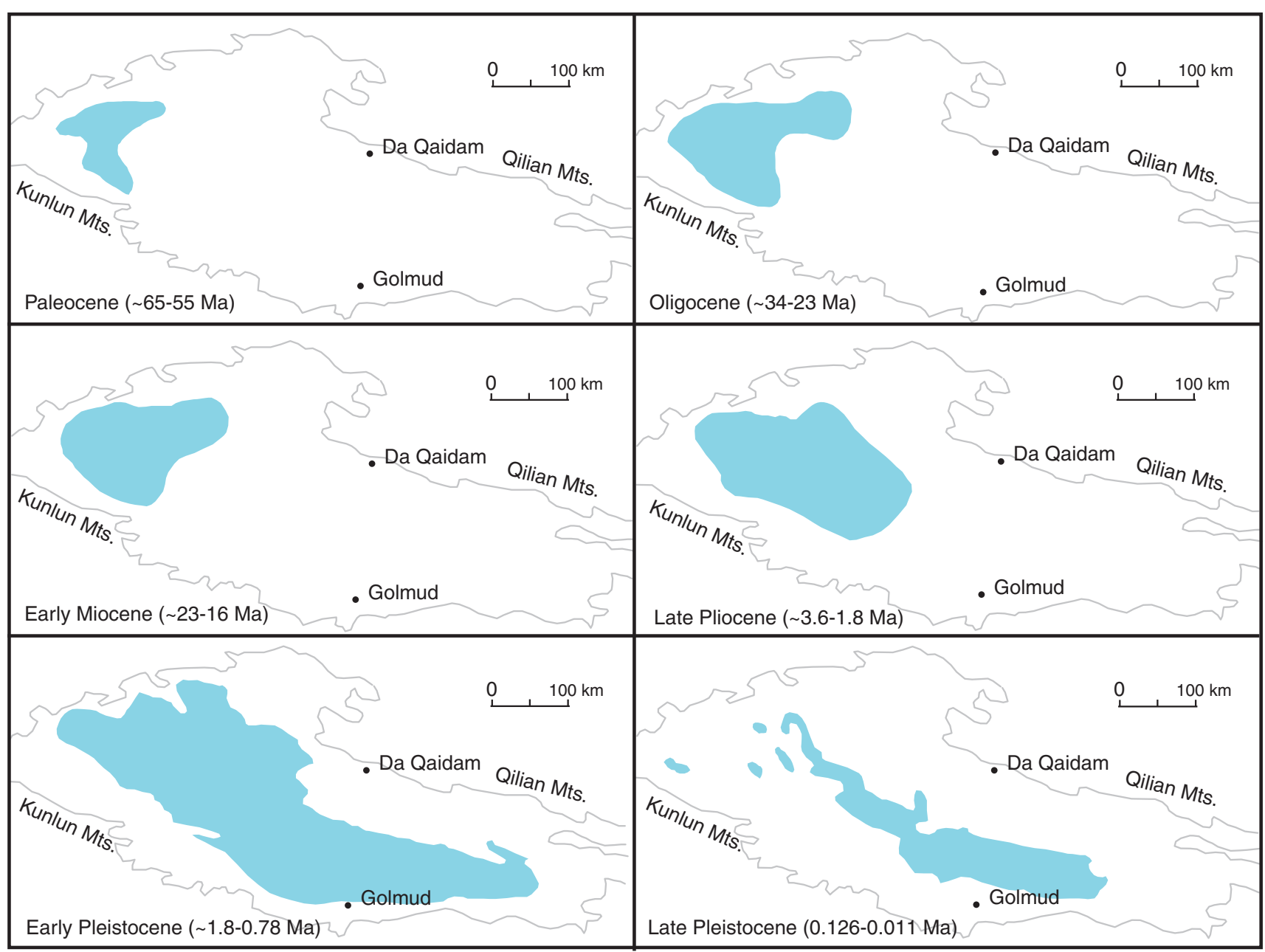

$\square$ Modern Basin Boundary $\square$ Paleolake

FIG. 2. Evolution of Paleocene-Late Pleistocene Qaidam Basin paleolake. Modified from Qi et al. (1993).

relatively bright in the ASTER VNIR color image (Fig. 1) tended to correlate with areas on the ground observed to be more gypsum-rich than areas that appear more dark-toned in the ASTER image.

The samples were sealed in double plastic bags to minimize transformation of the minerals during transport. Upon arrival to our laboratory, the samples were placed in a freezer, where the temperature fluctuated between $-9^{\circ} \mathrm{C}$ and $-11^{\circ} \mathrm{C}$. We monitored the samples periodically and we did not observe transformation during storage. To further reduce the chance of transformation (e.g., through dehydration and rehydration), we analyzed the samples within weeks of collection.

\subsection{Orbital remote sensing}

We used ASTER Level-1B radiance-at-sensor products as the basis for our orbital remote sensing analysis. ASTER data products are available through the NASA EarthData portal (https://earthdata.nasa.gov). Radiance from ASTER's VNIR and SWIR subsystems was reduced to surface reflectance values by using the fast line-of-sight atmospheric analysis of spectral hypercubes (FLAASH) algorithm (Berk et al., 1999). Radiance data from ASTER's TIR subsystem was converted
Table 2. Spectral Bandpasses and Spatial Resolution of Bands in Each of Advanced SpaCeborne Thermal Emission and Reflection Radiometer's Three Subsystems

\begin{tabular}{lccc}
\hline Subsystem & Band No. & $\begin{array}{c}\text { Spectral } \\
\text { range }(\mu \mathrm{m})\end{array}$ & $\begin{array}{c}\text { Spatial } \\
\text { resolution }(\mathrm{m})\end{array}$ \\
\hline VNIR & 1 & $0.52-0.60$ & 15 \\
& 2 & $0.63-0.69$ & \\
& $3 \mathrm{~N}$ & $0.78-0.86$ & \\
SWIR & $3 \mathrm{~B}$ & $0.78-0.86$ & \\
& 4 & $1.600-1.700$ & 30 \\
& 5 & $2.145-2.185$ & \\
& 6 & $2.185-2.225$ & \\
TIR & 7 & $2.235-2.285$ & \\
& 8 & $2.295-2.365$ & \\
& 9 & $2.360-2.430$ & \\
& 10 & $8.125-8.475$ & 90 \\
& 11 & $8.475-8.825$ & \\
& 12 & $8.925-9.275$ & \\
& 13 & $10.25-10.95$ & \\
\hline
\end{tabular}

SWIR $=$ shortwave infrared; TIR $=$ thermal infrared; VNIR $=$ vis ible near-infrared. 


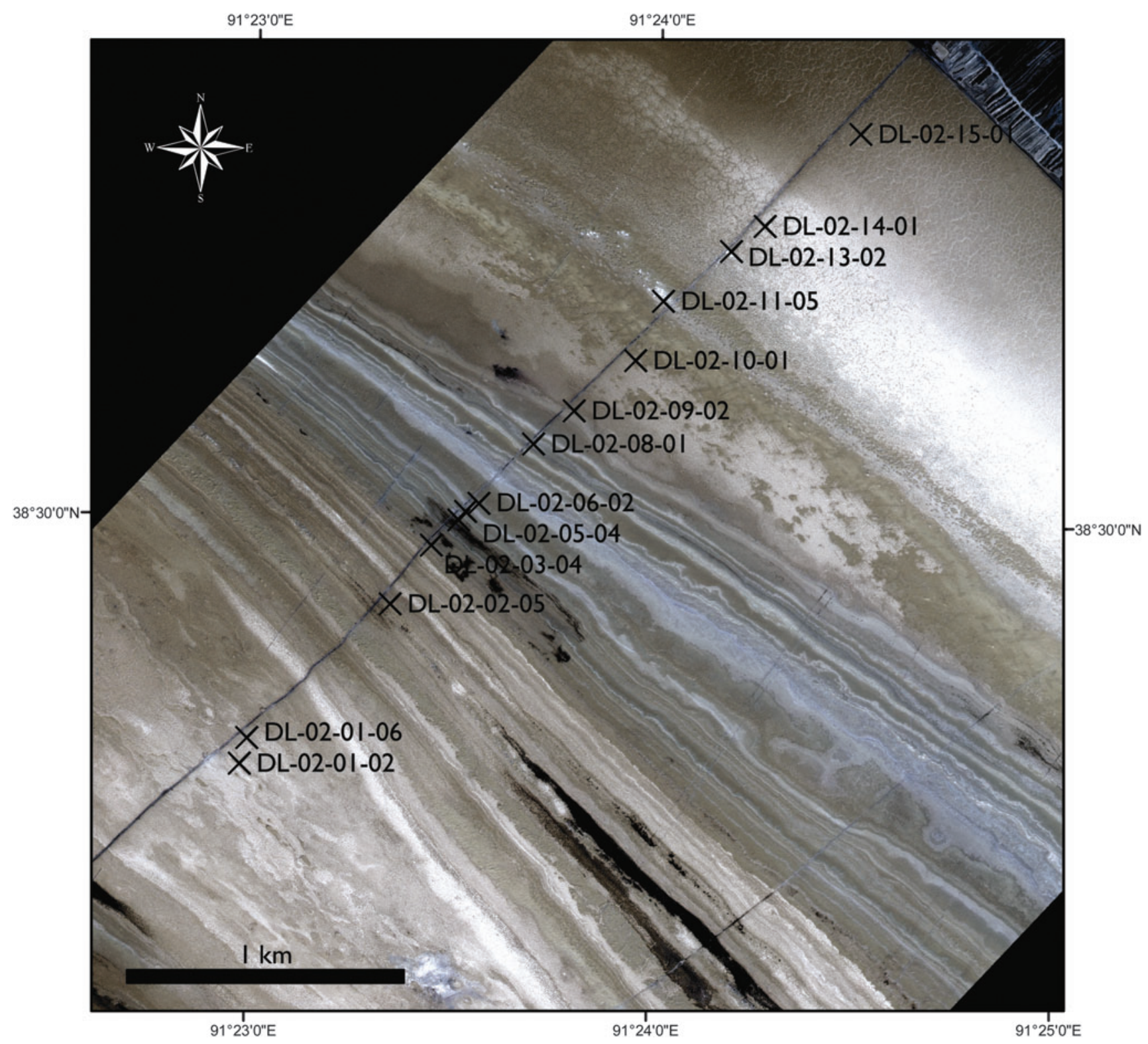

FIG. 3. Pan-sharpened QuickBird image provides a high-resolution view of the northeastern limb of Xiaoliangshan and sample collection sites.

TABLe 3. InPut Parameters Used For FLAASH CORRECTION

\begin{tabular}{lc}
\hline Parameter & Value \\
\hline Scene ID & AST L1B 00308152004044952 \\
& 20080813134807 20478 \\
Data acquired & August 15, 2004 \\
Scene center location & $38^{\circ} 24^{\prime} 18.37^{\prime \prime} \mathrm{N}, 91^{\circ} 21^{\prime} 31.33^{\prime \prime} \mathrm{E}$ \\
$\quad$ & \\
$\quad$ (degrees, minutes, & \\
Seconds) & 705 \\
Averor altitude (km) & 2.8 \\
$\quad$ elevation (km) & \\
Atmospheric model & Midlatitude summer \\
Initial visibility (km) & 40 \\
Aerosol scale height $(\mathrm{km})$ & 2 \\
CO ${ }_{2}$ mixing ratio $(\mathrm{ppm})$ & 390 \\
MODTRAN resolution & $5 \mathrm{~cm}^{-1}$ \\
\hline
\end{tabular}

to relative emissivity by using the alpha residuals algorithm (Hook et al., 1992). The alpha residuals technique uses Wien's approximation of the Planck function to linearize the equation and log averages to remove the kinetic temperature term. The resultant alpha residual spectra have a mean of zero but display the same shape as absolute emissivity spectra.

Map units were defined based on spectrally distinct signatures extracted separately from reflectance and qualitative emissivity data. The band centers in ASTER's VNIR and SWIR subsystems (Table 2) allow identification of charge transfer/electronic transition absorptions, metal-OH combination bands, and carbonate-related absorptions (Clark, 1999). The band centers in ASTER's TIR subsystem (Table 2) enable discrimination between felsic versus mafic composition as well as identification of sulfates and carbonates from fundamental molecular absorption features (Salisbury and D'Aria, 1994). Table 3 lists the input parameters for the 

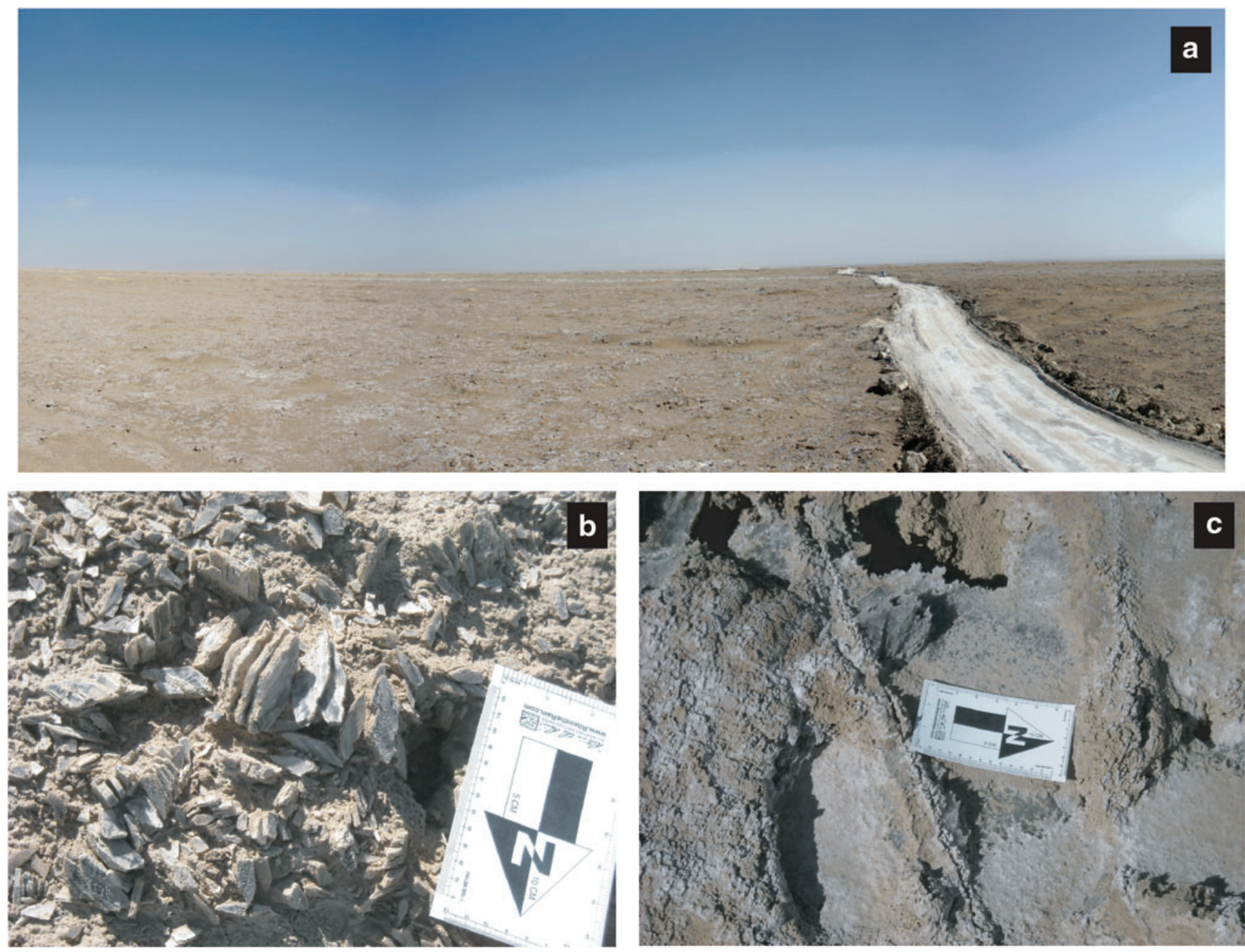

FIG. 4. Field photos from Xiaoliangshan traverse. Scale on arrow is $10 \mathrm{~cm}$ long. (a) Panorama showing view to northeast along traverse. Road is $3.5 \mathrm{~m}$ wide. (b) Gypsum efflorescence typical of much of the surface of the field area. (c) Halite surface crust with efflorescence on edge of desiccation crack.

ASTER scene used in this study. The wavelength range of ASTER's TIR sensors lies within the $8-14 \mu \mathrm{m}$ atmospheric transmission window, thus minimizing the need to perform an atmospheric correction of the data.

\subsection{In situ sensing}

We recorded near-infrared (NIR; $1.25-2.5 \mu \mathrm{m})$ reflectance spectra at each of the sampling sites along the traverse route shown in Figure 3 without any sample preparation. All spectra were recorded in $30 \mathrm{~s}$ long integrations and relative to a halon white reference. We used the water infrared (WIR) instrument, a prototype instrument developed at Washington University in St. Louis (WUSTL) (Wang et al., 2010a; Wang, 2013; Sobron and Wang, 2017). WIR is a miniaturized, fieldready, active source NIR $(1.14-4.76 \mu \mathrm{m})$ reflectance spectrometer that enables in situ, near real-time identification of water (structural or adsorbed), carbonates, sulfates, hydrated silicates, as well as $\mathrm{C}-\mathrm{H}$ and $\mathrm{N}-\mathrm{H}$ bonds in organic species.

WIR is suited for lander/rover deployment in two modes: (1) In traverse survey mode, WIR is integrated into a rover wheel and performs nonstop synchronized data collection with every revolution of the wheel; large amounts of data points can be collected during a rover traverse that inform the spatial distribution of mineral phases; (2) In point-check mode, WIR is mounted on a robotic arm of a rover/lander and deployed on selected targets at planetary surfaces, or installed inside an analytical laboratory where samples from a drill/scoop are delivered for detailed analysis.

During our field campaign, we deployed the phase-II version of WIR (Fig. 5) with a field of view of $2.5 \mathrm{~cm}$, volume of $10 \times 7.5 \times 6.5 \mathrm{~cm}$, mass of $450 \mathrm{~g}$, power consumption of $4 \mathrm{~W}$, and USB data outputs. It covers a spectral range from 1.25 to $2.5 \mu \mathrm{m}$ in 128 spectral channels. We fitted the WIR into a ruggedized housing that enabled operation in the dusty and cold environment of the Qaidam Basin.

\subsection{Laboratory analyses}

3.4.1. VNIR reflectance (VNIR spectroscopy). We measured VNIR reflectance spectra using a FieldSpecProFR from Analytical Spectral Devices, Inc. with a contact probe and solar-simulated light source. Spectra were measured relative to a halon white reference; field of view was $\sim 1 \mathrm{~cm}$ across 


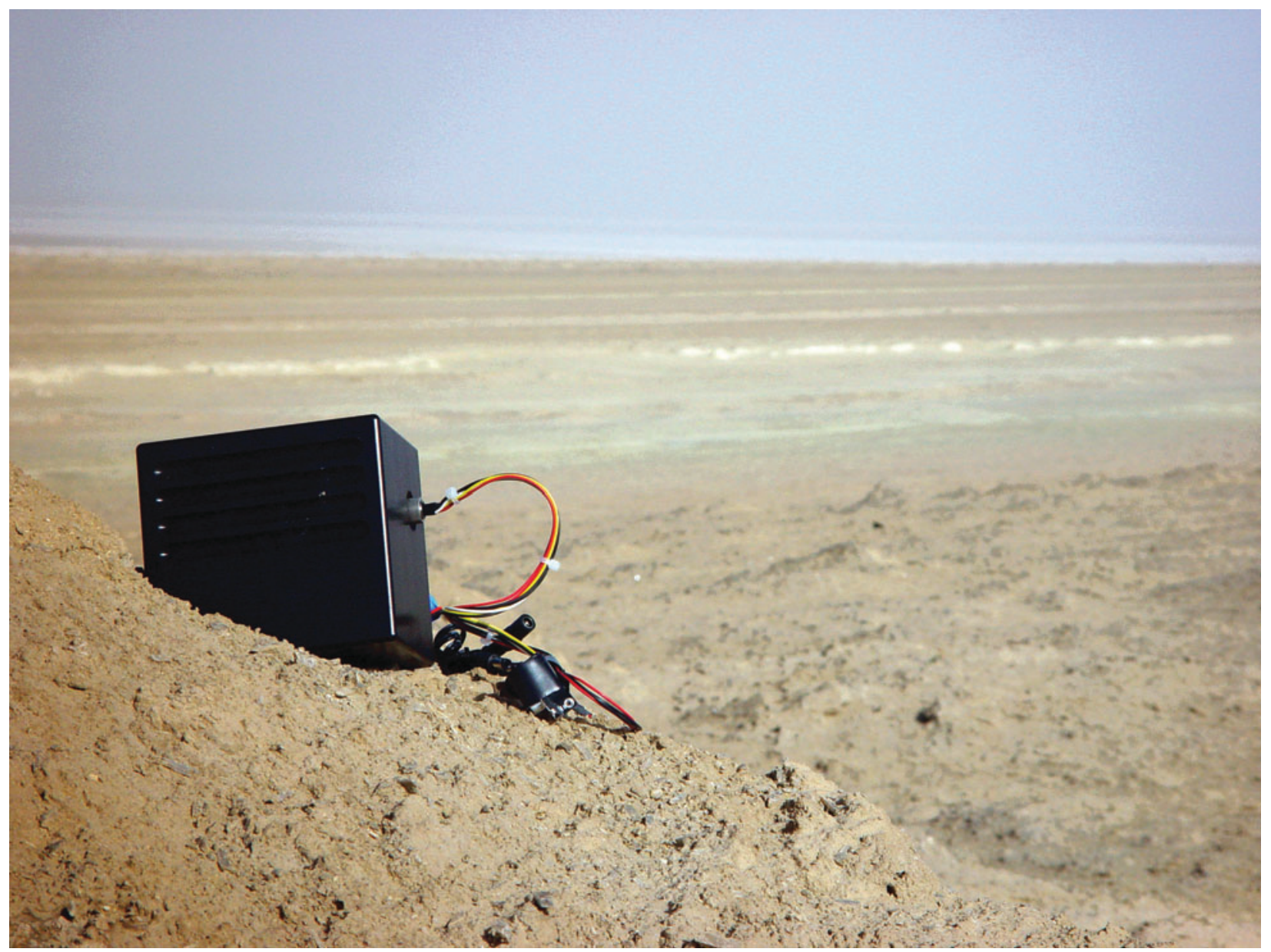

FIG. 5. WIR II instrument recording in situ NIR spectra at the Xiaoliangshan anticline in the Qaidam Basin (Tibet Plateau, China). NIR, near-infrared; WIR, water infrared.

on the rock surfaces; spectral resolution was $2 \mathrm{~nm}$; and spectral range was $0.35-2.50 \mu \mathrm{m}$. We collected spectra at several locations on the rock surfaces without preparation. The spectral response of this instrument was calibrated before sample analyses by using atomic emission lines from a lowpressure NIST-traceable gas emission lamp. Each spectrum was averaged over 50 scans.

3.4.2. Laser Raman spectroscopy. We recorded Raman spectra from returned samples using a HoloLab5000-532 laser Raman spectrometer (Kaiser Optical Systems, Inc.). The instrument utilizes the 532-nm line of a frequency-doubled CW Nd:YAG laser as the excitation source. The spectrometer covers a spectral range of $100-4000 \mathrm{~cm}^{-1}$ with a spectral resolution of $4 \mathrm{~cm}^{-1}$. A $20 \times$ microscope objective $(0.4 \mathrm{NA})$ with a working distance of $1 \mathrm{~cm}$ was used for these measurements. This objective produces a condensed laser beam of $6 \mu \mathrm{m}$ diameter at the focus.

Wavelength calibration of the Raman spectrometer was carried out by using a neon emission lamp. The spectral intensity was corrected against a secondary intensity standard tungsten lamp. The laser wavelength was checked on each working day by using the Raman peak of a Si wafer at $520.7 \mathrm{~cm}^{-1}$ at $20^{\circ} \mathrm{C}$, and this was corrected to be within $\pm 0.2 \mathrm{~cm}^{-1}$. The wavelength accuracy and precision were better than $1 \mathrm{~cm}^{-1}$ in the spectral region of interest. Samples were analyzed without preparation. An average of at least five spots were analyzed on the surface of each of the samples, thus mitigating inhomogeneities in the samples.

3.4.3. X-ray diffraction and X-ray fluorescence. Each XRD subsample was ground with a mortar and pestle and sieved to $150 \mu \mathrm{m}$. We performed bulk powder XRD analyses using inXitu's Terra instrument, a field-portable version of the CheMin instrument aboard NASA's Mars Science Laboratory mission (Sarrazin et al., 2008; Blake et al., 2012). Terra is able to collect X-ray photon data for both XRD and X-ray fluorescence (XRF) simultaneously. It utilizes a $\mathrm{CoK} \alpha \mathrm{X}$-ray tube, and its $2 \theta$ range is $4-55^{\circ}$. We ran the instrument in the "default" setting using the clear Mylar window in the sample holder. For each sample, between 50 and 250 exposures were used depending on the noise in the diffractograms. The data were analyzed with XPowder software (www.xpowder.com).

3.4.4. Laser-induced breakdown spectroscopy. We powdered and pressed material subsampled from the returned 
samples into $2 \mathrm{~cm}$ diameter pellets suitable for bulk LIBS analyses. We analyzed an average of 5 spots across the surface of each of the sample pellets; 25 single-shot spectra were recorded at each spot, yielding 125 spectra per sample. Our custom-built laboratory LIBS setup uses an actively Qswitched Nd:YAG Minilite-II laser from Continuum: $7 \mathrm{~ns}$ pulse width, maximum $45 \mathrm{~mJ} /$ pulse, $1064 \mathrm{~nm}$ wavelength, and an Andor Mechelle 5000 spectrograph equipped with an intensified CCD detector (Andor iStar 712).

The front optics includes a dichroic mirror to direct the $1064 \mathrm{~nm}$ laser pulse into a $5 \times$ microscope objective lens assembly (OFR LMH-5X-1064) that focuses the laser pulse onto the sample surface for LIBS excitation, with a spot diameter of $\sim 100 \mu \mathrm{m}$. A bare ultraviolet (UV)-enhanced optical fiber ( $230 \mu \mathrm{m}$ core diameter) positioned at $\sim 10 \mathrm{~mm}$ and $45^{\circ}$ from the surface of the sample collects the light from the plasma emission. The other end of the collection optical fiber is connected to the high-resolution broadband spectrometer assembly. In this work, we used a $50 \mu \mathrm{m}$ entrance slit, which enables analyses in the $200-950 \mathrm{~nm}$ spectral range with a wavelengthdependent spectral resolution ranging from 0.04 to $0.1 \mathrm{~nm}$.

The spectra were collected with a $700 \mathrm{~ns}$ delay, and the integration time was set to $4 \mu \mathrm{s}$. The spectrometer was wavelength calibrated by using 10 atomic emission lines from an NIST-traceable $\mathrm{Hg} / \mathrm{Ar}$ lamp. To correct the overall spectral response of the whole system, especially the nonlinear efficiency of the dispersion grating in the Echelle spectrograph and the spectral response of detector, an NISTtraceable dual deuterium/quartz tungsten halogen lamp was used as intensity standard.

\section{Results}

\subsection{Orbital remote sensing}

A three-step approach was used to define spectral units for the VNIR/SWIR and TIR image data: (1) suppression of noise from the image data, (2) tabulation of the most spectrally pure pixels in the image, and (3) selection of groups of spectrally distinct pixels that represent spectral end-members within the scene. These processing steps were applied separately to the VNIR/SWIR reflectance data and to the TIR relative emissivity data from the ASTER image. Spectral units were also extracted from the VNIR/SWIR reflectance data for a spatial subset that contains the XLS anticline to thoroughly explore the spectral properties of the sequence of lacustrine deposits exposed at the surface of the structure.

First, a minimum noise fraction (MNF) transformation was applied to each data set to enhance subtle absorption features and suppress noise (Green et al., 1988). The MNF transform consists of two cascaded principle component transforms. The first principle component transform is computed for an estimated noise covariance matrix based on pixel-to-pixel variations in the data to identify and scale noise to unit variance (Green et al., 1988). The second principle component transform is performed on the result of the first transform to produce a series of eigenimages with gradually decreasing eigenvalues. Eigenimages with relatively high eigenvalues display the largest variance and smallest amount of noise.

Areas of the ASTER scene that appeared to contain clouds or open water were masked out before applying the MNF transform to prevent these areas from driving the variance of the scene and making it more difficult to identify geologi- cally interesting spectral end-members. Data from the MNF eigenimages were subsequently analyzed by using Boardman's Pixel Purity Index (PPI) method (Boardman et al., 1995). The PPI method repeatedly projects $n$-dimensional vectors from the eigenimages randomly onto $n$-dimensional unit vectors. Pixels that most frequently appear at the outer edges of the distribution when projected along a given unit vector are considered more spectrally pure.

The top few percent of the most spectrally pure pixels as determined by the PPI were then examined in an $n$-dimensional space to select spectrally similar groups of pixels as spectral end-members. Only spectrally similar groups of pixels that were geographically colocated were accepted as spectral endmembers. These spectral end-members serve as the basis for the spectral units mapped and defined hereunder.

4.1.1. VNIR/SWIR spectral units. We identified eight distinctive spectral units-end-members-from the ASTER VNIR/SWIR data within the full scene (Fig. 6). We show the type locations for these spectral units in Figure 1. The spectral unit names are based on the wavelength range (V for VNIR/ SWIR), an abbreviation for the type location and a sequence number to distinguish different units found in the same general location. The eight spectral end-members display several common reflectance features (Fig. 6). All of the spectral units show a distinct increase in reflectance from 0.5 to $0.8 \mu \mathrm{m}$, likely due to $\mathrm{Fe}^{3+}$ charge transfer absorption centered in the UV and narrower associated features located near 0.5 and $0.9 \mu \mathrm{m}$ (Morris et al., 1985; Clark, 1999).

The VNIR portion of these end-member spectra are distinguished by small variations in their slope. A subtle concave feature located in the second ASTER band of spectral unit VFLR1 may be due to a $\mathrm{Fe}^{3+}$ absorption centered near $0.68 \mu \mathrm{m}$. Interpretation of the $\mathrm{Fe}^{3+}$ absorption features is difficult because their relative depth not only varies with mineralogy but is also dependent on grain size, iron oxide concentrations, and matrix effects (Morris et al., 1989; Morris and Lauer, 1990). Furthermore, shifts in the location of $\mathrm{Fe}^{3+}$ absorption features will cause the features to be spectrally undersampled by ASTER because of the instrument's limited spectral coverage between 0.5 and $0.8 \mu \mathrm{m}$.

The VNIR/SWIR spectral end-members show the greatest variability at wavelengths $>1.65 \mu \mathrm{m}$. These spectra show several shallow absorption features superposed on an overall negative slope from 1.65 to $2.4 \mu \mathrm{m}$. Units VYSS1, VXLS2, VFLR3, and VFLR1 show a distinct absorption feature at $2.2 \mu \mathrm{m}$. The remaining spectral units show absorptions at $2.1 \mu \mathrm{m}$ with shoulders at $2.2 \mu \mathrm{m}$. Absorption near $2.2 \mu \mathrm{m}$ is associated with Al-OH vibrational mode typically found in dioctahedral varieties of illite $\left(\left(\mathrm{K}, \mathrm{H}_{3} \mathrm{O}\right)(\mathrm{Al}, \mathrm{Mg}, \mathrm{Fe})_{2}(\mathrm{Si}, \mathrm{Al})_{4} \mathrm{O}_{10}\left[(\mathrm{OH})_{2},\left(\mathrm{H}_{2} \mathrm{O}\right)\right]\right)$ and smectite (a hydrous aluminum silicate containing iron, magnesium, and either sodium or calcium) as well as a combination of the $\mathrm{OH}$ stretch and structural water libration in gypsum $\left(\mathrm{Ca}_{2} \mathrm{SO}_{4} \cdot 2 \mathrm{H}_{2} \mathrm{O}\right)$ (Clark, 1999; Crowley, 1991).

Kaolinite $\left[\mathrm{Al}_{2} \mathrm{Si}_{2} \mathrm{O}_{5}(\mathrm{OH})_{4}\right]$ contains a diagnostic absorption doublet with reflectance minima centered at 2.17 and $2.21 \mu \mathrm{m}$ due to combination $\mathrm{Al}-\mathrm{OH}$ bending and $\mathrm{OH}$ stretching modes. However, this doublet appears as a single reflectance minimum at $2.2 \mu \mathrm{m}$ in library reflectance spectra of kaolinite resampled to the ASTER bandpasses. Weak absorptions are seen near $2.3 \mu \mathrm{m}$ in spectral units VYSS1, VFAN, VYSS2, VFLR1, and VFLR3. Reflectance minima in this region can 


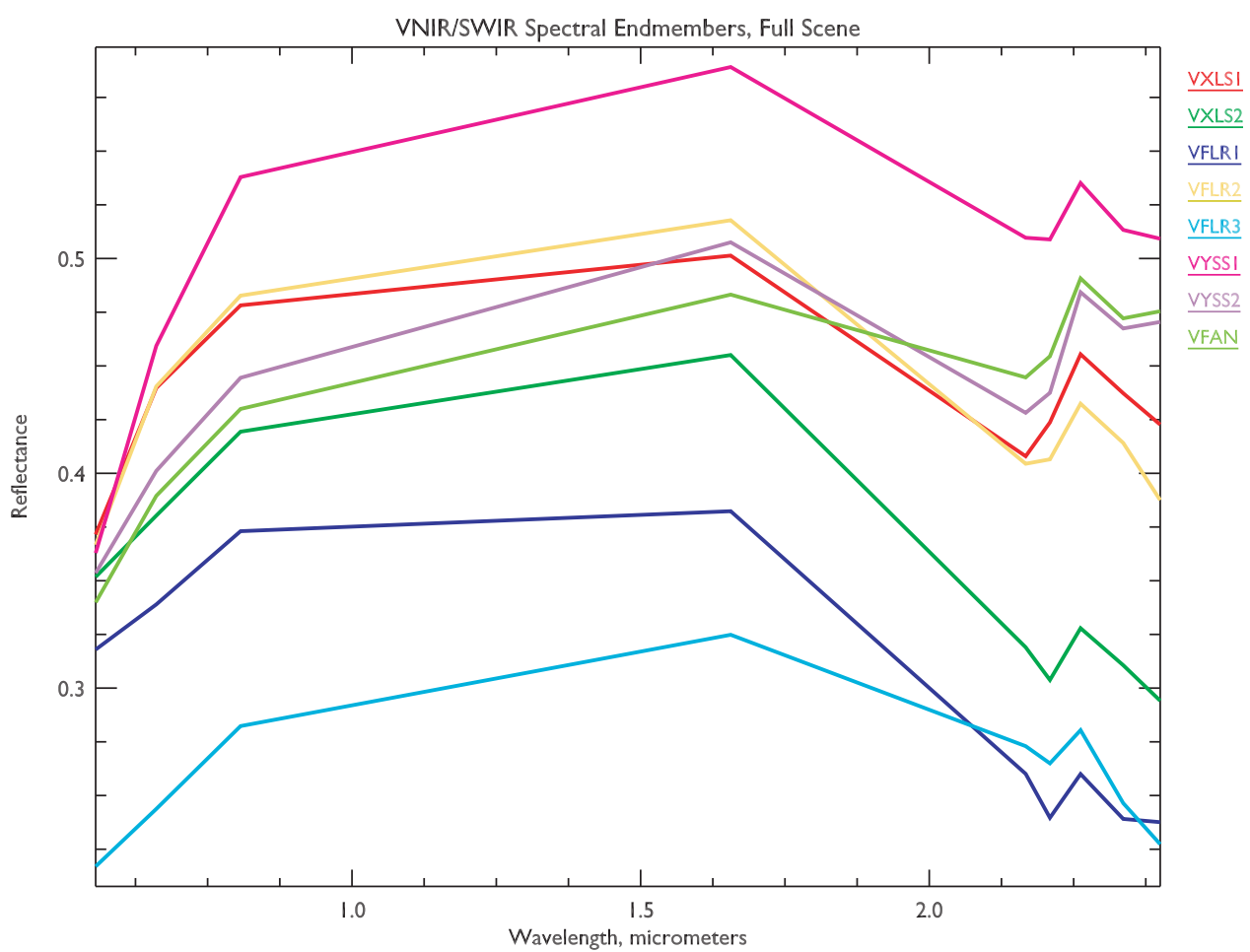

FIG. 6. ASTER spectra for eight VNIR/SWIR units. Each spectrum is an average of the purest pixels identified by PPI analysis over the full ASTER scene. PPI, Pixel Purity Index; SWIR, shortwave infrared.

be caused by combination of $\mathrm{CO}$ bending and stretching modes in anhydrous carbonates (Crowley, 1991; Ryerson et al., 1999) as well as by combination of $\mathrm{OH}$ stretching bending modes in illite and kaolinite or Mg phyllosilicates such as saponite, serpentine, or talc (Clark, 1999).
Owing to the ambiguities in the source of absorption features in the VNIR/SWIR spectral units, further interpretation of the mineralogy of ASTER VNIR/SWIR spectra is not possible.

Four spectral end-members have been identified from a spatial subset of the ASTER VNIR/SWIR data over the XLS

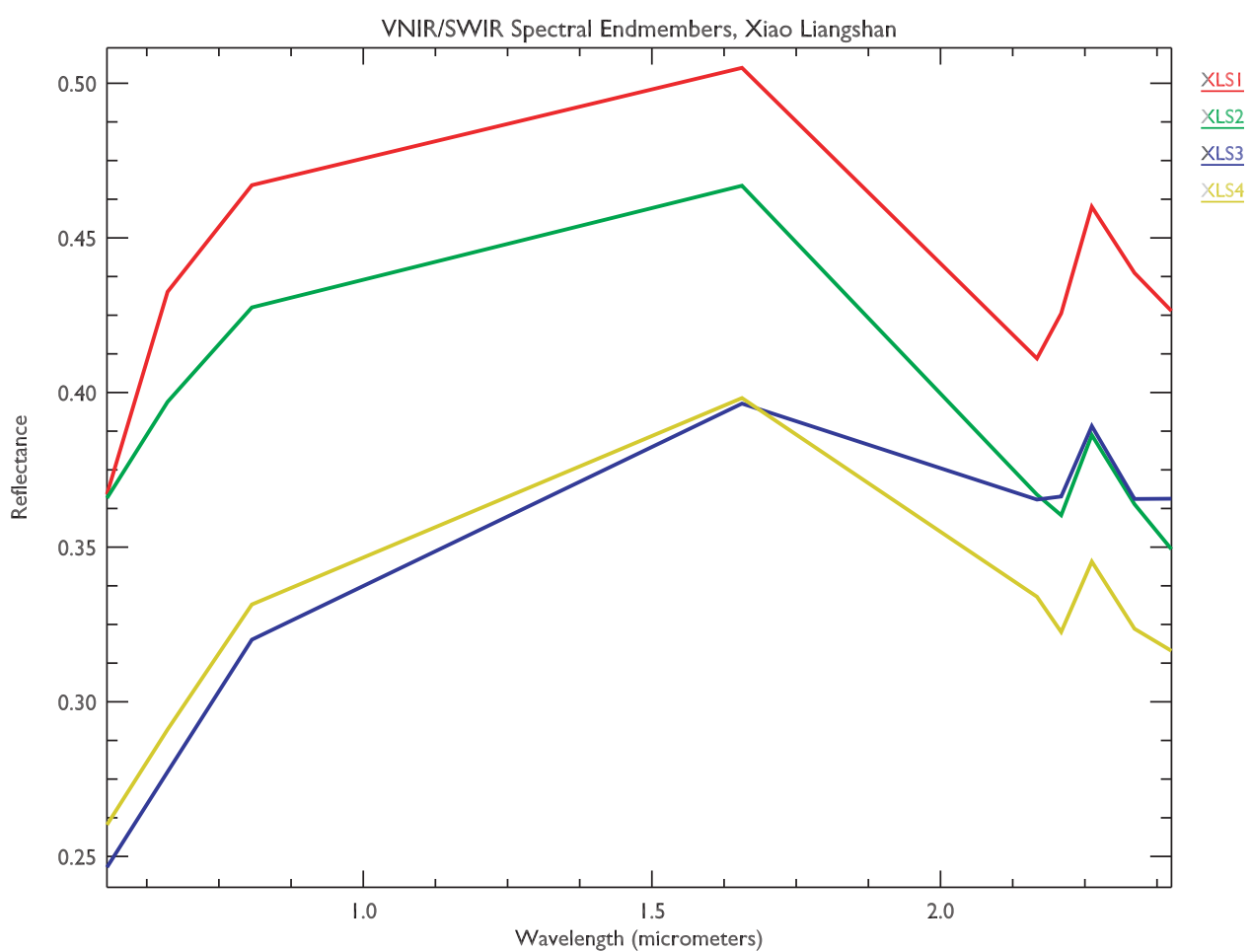

FIG. 7. ASTER spectra for four VNIR/SWIR units. Each spectrum is an average of the purest pixels identified by PPI analysis within the area that contains the Xiaoliangshan anticline. 
anticline (Fig. 7). We show the type locations for these spectral units in Figure 3. Spectral units are named after their location (XLS) and a sequence number. These four spectral units show remarkable similarities to one another. XLS1 and XLS2 show very similar slopes in the VNIR wavelength range although XLS1 displays a higher overall reflectance.

XLS3 and XLS4 are nearly identical between 0.56 and $1.65 \mu \mathrm{m}$, at which point the slope of XLS4's reflectance decreases more quickly than the slope of XLS3's reflectance. XLS2 and XLS4 each show strong absorption features at $2.2 \mu \mathrm{m}$. XLS3 contains an absorption at $2.2 \mu \mathrm{m}$ as a shoulder to a slightly deeper absorption feature. XLS3 also contains an absorption at $2.3 \mu \mathrm{m}$. Among the four spectral end-members, XLS1 is the only one that contains a strong absorption feature at $2.1 \mu \mathrm{m}$.

4.1.2. TIR spectral units. We identified four spectral endmembers from the ASTER TIR data within the full scene (Fig. 8). We show the type locations for these spectral units in Figure 1. The spectral units are named after a wavelength range (TIR) and a sequence number. Spectral unit TIR1 shows a strong absorption near $9 \mu \mathrm{m}$, which is characteristic of fundamental lattice vibrations in quartz $\left(\mathrm{SiO}_{2}\right)$ and alkali feldspars (a group of feldspar minerals rich in sodium and potassium) (Salisbury and D'Aria, 1994).

The distinct absorptions seen at $8.6 \mu \mathrm{m}$ in units TIR3 and TIR4 are most likely due to fundamental lattice vibrational modes in sulfates (Salisbury and D'Aria, 1994). Comparison of spectral units TIR3 and TIR4 with emissivity library spectra (Christensen et al., 2000; Lane, 2007) convolved to the ASTER TIR bandpasses (Fig. 9) suggests that these end-members could be composed of one or more sulfates including gypsum, anhydrite $\left(\mathrm{CaSO}_{4}\right)$, or bassanite $\left(\mathrm{CaSO}_{4} \bullet 1 /\right.$ $2 \mathrm{H}_{2} \mathrm{O}$ ). The distinct positive slope present in all four spectral units may be due to overlapping atmospheric water and carbon dioxide bands centered near $8 \mu \mathrm{m}$.

Besides the positive slope seen in all four spectra, spectral unit TIR2 appears flat and featureless. The lack of spectral features in ASTER TIR emissivity data has been used to infer the presence of halite $(\mathrm{NaCl})$ in other studies of playa materials (Crowley and Hook, 1996; Baldridge et al., 2004). On this basis, we suggest unit TIR2 is dominated by halite. This interpretation is further supported by field observations of halite crusts along the XLS traverse (Fig. 4c), including near the top of the anticline, consistent with the classification map.

4.1.3. Spatial distribution of spectral units. We used the ASTER VNIR/SWIR and TIR spectral end-members defined in the previous section to generate classification maps showing the distribution of these materials within the ASTER scene. We generated classification maps using the Spectral Angle Mapper (SAM) method (Kruse et al., 1993).

The SAM method treats spectra as $n$-dimensional vectors and computes the angle between two spectra in $n$-dimensional space, where $n$ is the number of bands in the image data. The angle is calculated from the dot product of two vectors where one vector is the spectrum of a given ASTER pixel and the other is one of the end-member spectra. Small separation angles between two spectral vectors indicate spectral similarity. The SAM method, therefore, depends on the shape of a particular spectrum rather than absolute reflectance values. This makes the method relatively insensitive to illumination differences.

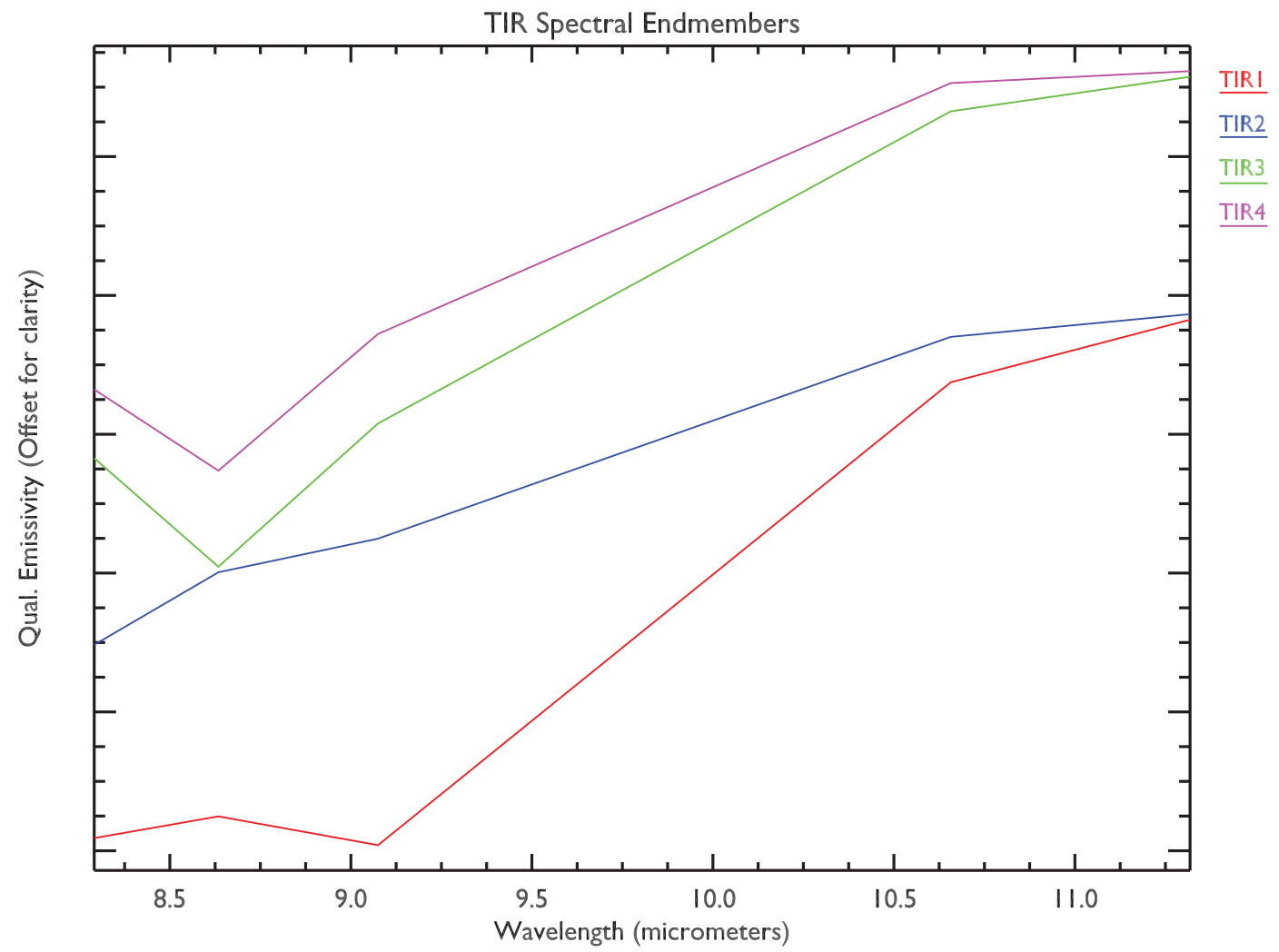

FIG. 8. ASTER spectra for four TIR units. Each spectrum is an average of the purest pixels identified by PPI analysis over the full ASTER scene. TIR, thermal infrared. 


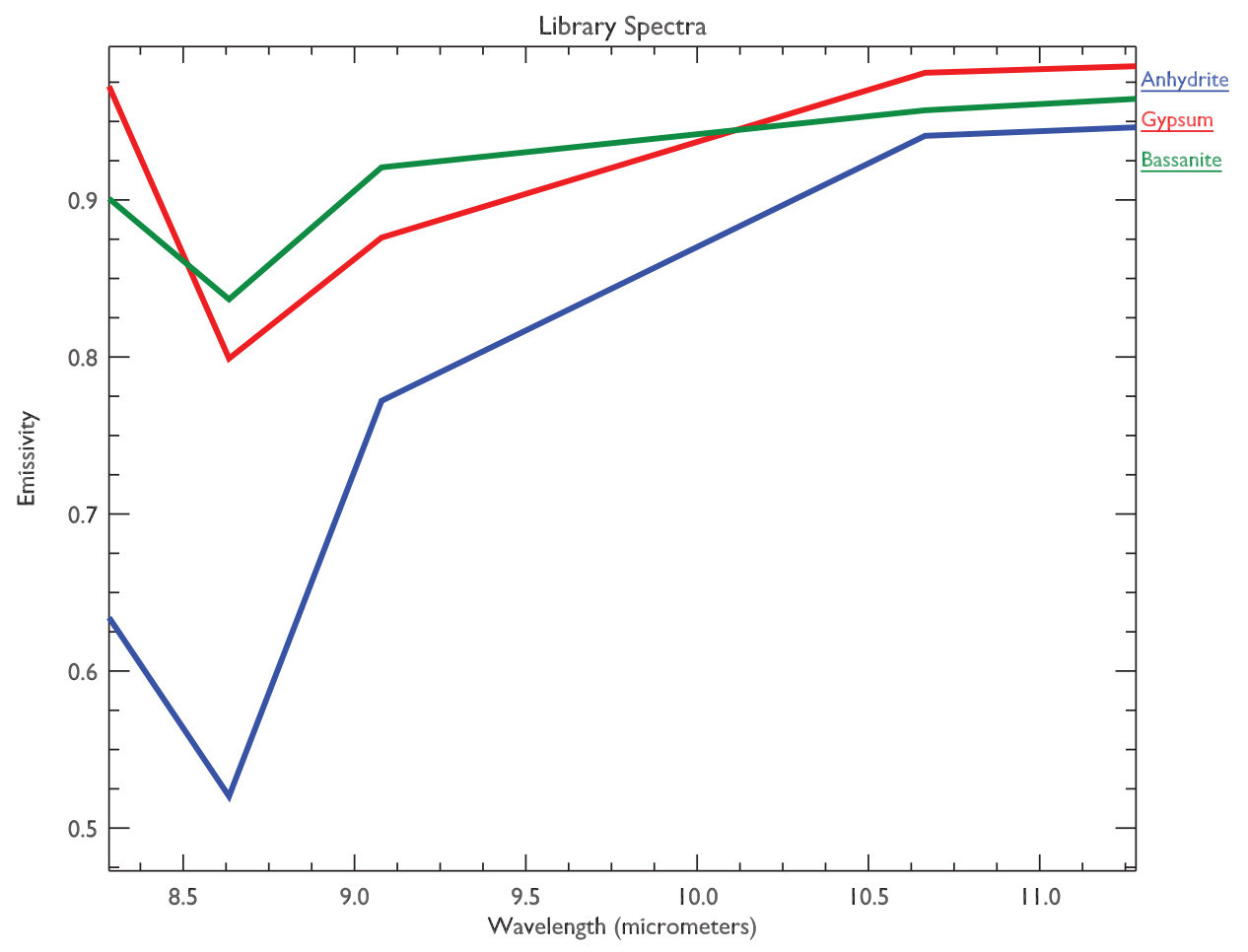

FIG. 9. Mineral emissivity library spectra (Christensen et al., 2000; Lane, 2007) resampled to ASTER TIR bandpasses for comparison with TIR unit spectra.

We used the spectral end-members shown in Figures 6, 7, and 8 as reference spectra to generate three classification maps for the full VNIR/SWIR scene, VNIR/SWIR data from the XLS subset, and the full TIR scene, respectively. Pixels in the ASTER image are assigned to a particular spectral class if the separation angle from the reference is within a particular threshold. Pixels that fall outside of the threshold when compared with all of the reference spectra are not classified. Thresholds of $0.035,0.020$, and 0.0100 radians were used for the full scene VNIR/SWIR, subset VNIR/SWIR, and full scene TIR maps, respectively. The specific threshold values used in this study represent a compromise between the number of pixels classified and how closely the pixels in the scene match a given spectral end-member.

Results of the SAM analysis of the VNIR/SWIR spectral end-members derived from the full ASTER scene (Fig. 10) reveal a sequence of spectral units that can be correlated among the four anticlinal domes in the image. The three largest anticlinal domes, particularly the unnamed anticline at the western edge of the ASTER scene, show exposures of the VFAN unit in close association with the VYSS2 unit. These two units appear to intermingle somewhat near the top of Nanyishan and the anticline at the eastern edge of the scene. The VYSS2 unit is distributed concentrically about the VFAN unit at the top of the western anticline. The correlation of units between these three anticlines becomes less clear toward their outer edges, where exposed deposits become thinner and fall below the resolution limit of the instrument.

The anticline at the eastern edge of the ASTER scene displays an alternating sequence of VYSS1 and VYSS2 material that appears to repeat twice, moving concentrically outward from the structure's center. This same anticline also displays several distinct layers of VXLS2 and VFLR2 material on its southern flank that appear to be truncated at an unconformity. The portion of the Yushashan anticline visible on the southwestern corner of the ASTER scene shows surface material that is dominated the VYSS2 unit in areas that are immediately upslope from alluvial fans that point into the basin. By contrast, areas of Yushashan that do not appear to be sources of alluvial material are dominated by the VFAN spectral unit.

Classified pixels of the basin floor are mostly restricted to the northern half of the scene, where VFAN material is widespread. An exposure of VYSS2 material forms a nearly continuous concentric arc with respect to the broader exposure of the VFAN material. This concentric exposure appears to parallel the local topographic contours. Several similar thin exposures of VYSS2 and VYSS1 material are observed along the northern margin of the basin in the ASTER scene.

XLS displays a strikingly different sequence of spectral units from those observed on the other anticlines. The northwestern and southeastern ends of XLS contain several exposures of VXLS1 material that appears to grade into VFLR2 material along the flanks of the anticline. A large exposure of VXLS2 occurs on the southern end of the northeastern flank of the anticline.

The classified pixels on XLS are almost exclusively composed of material that appears bright in the VNIR bands, whereas the darker layers on the anticline do not appear to be spectrally related to the VNIR/SWIR end-members derived from the full ASTER scene. Results from the SAM analysis of the VNIR/SWIR spectral end-members derived from the subset of the ASTER scene over XLS are shown in Figure 11. These show a repeating sequence of several endmembers within the layers of the anticline. In particular, 


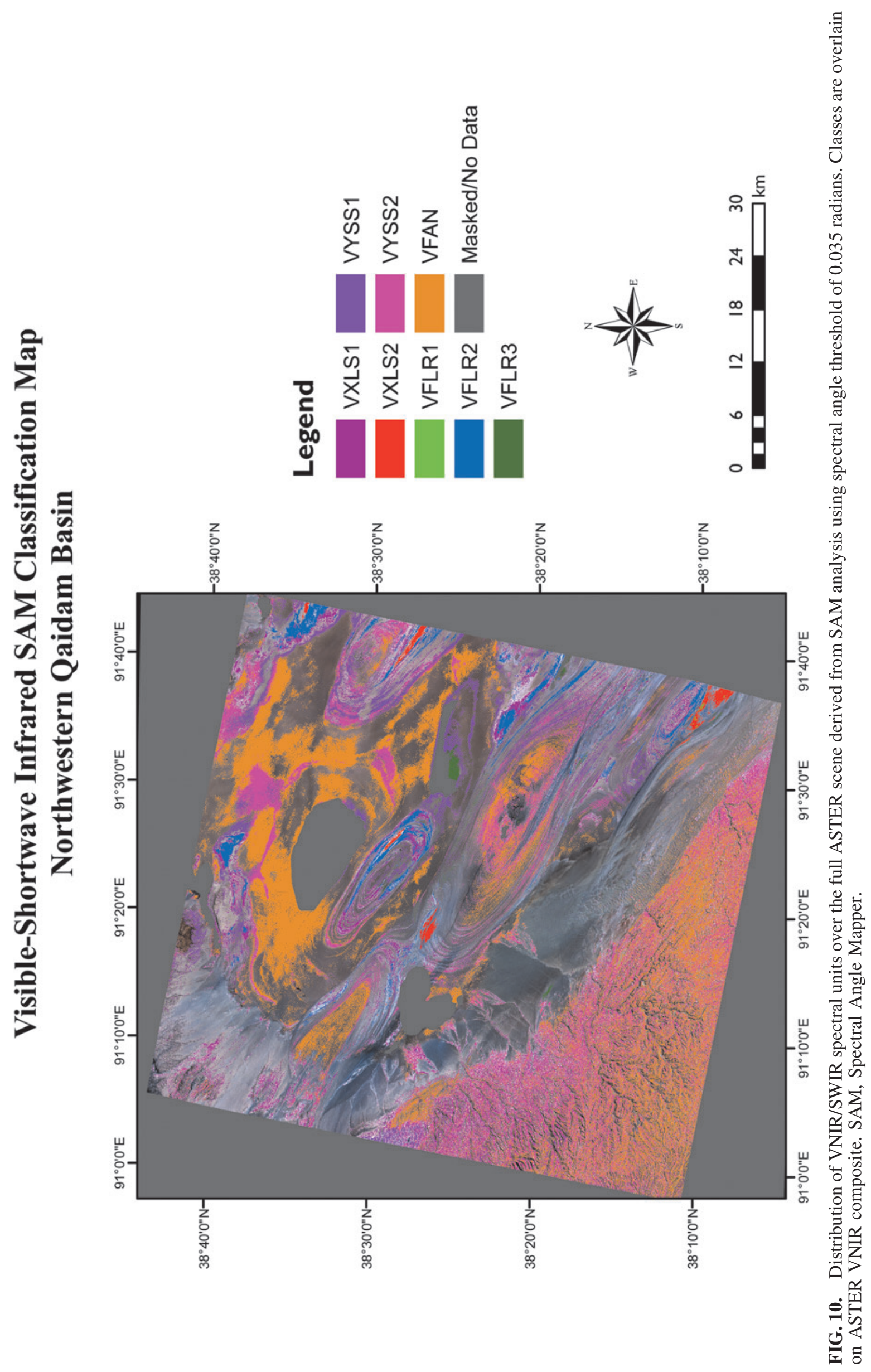




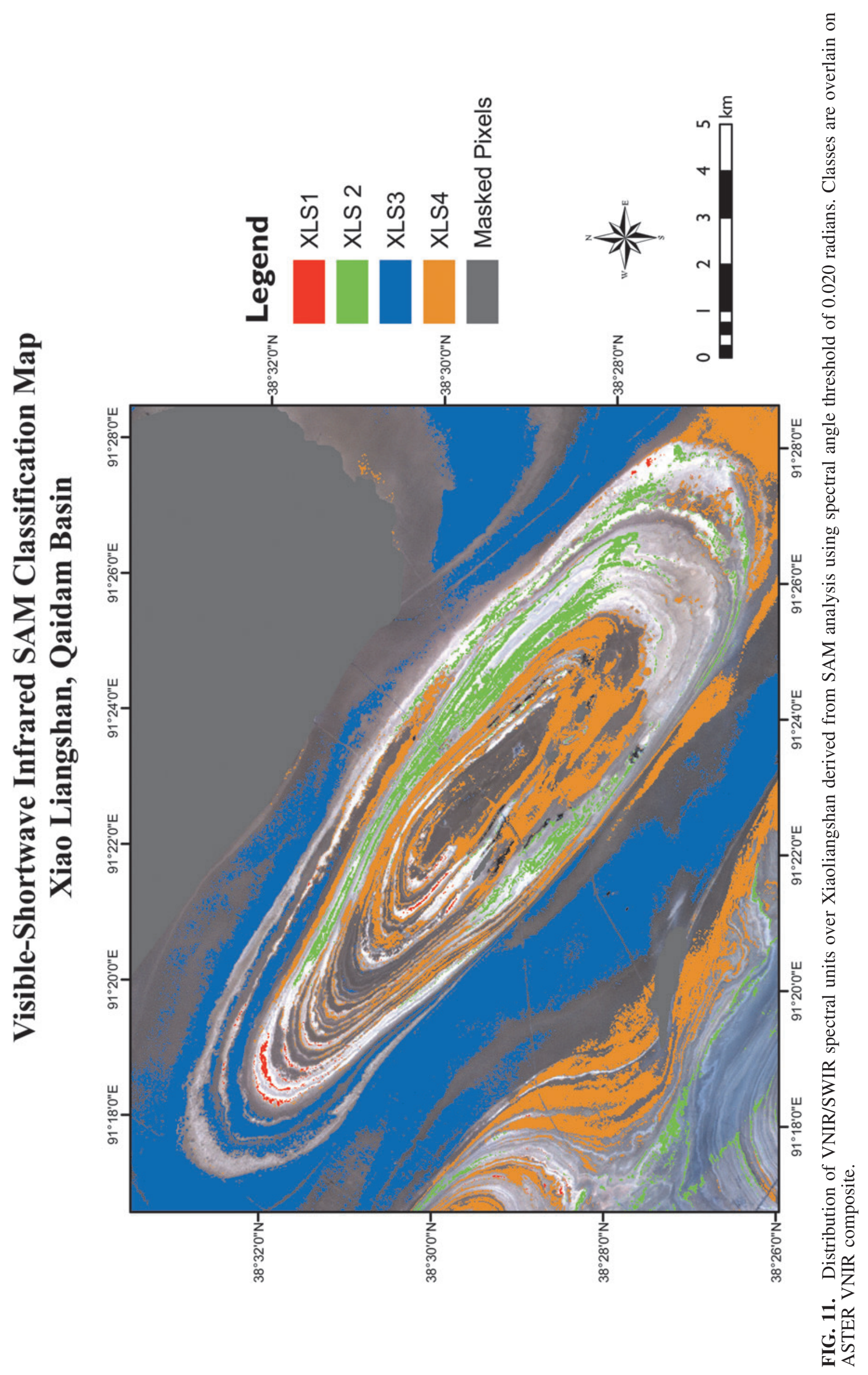




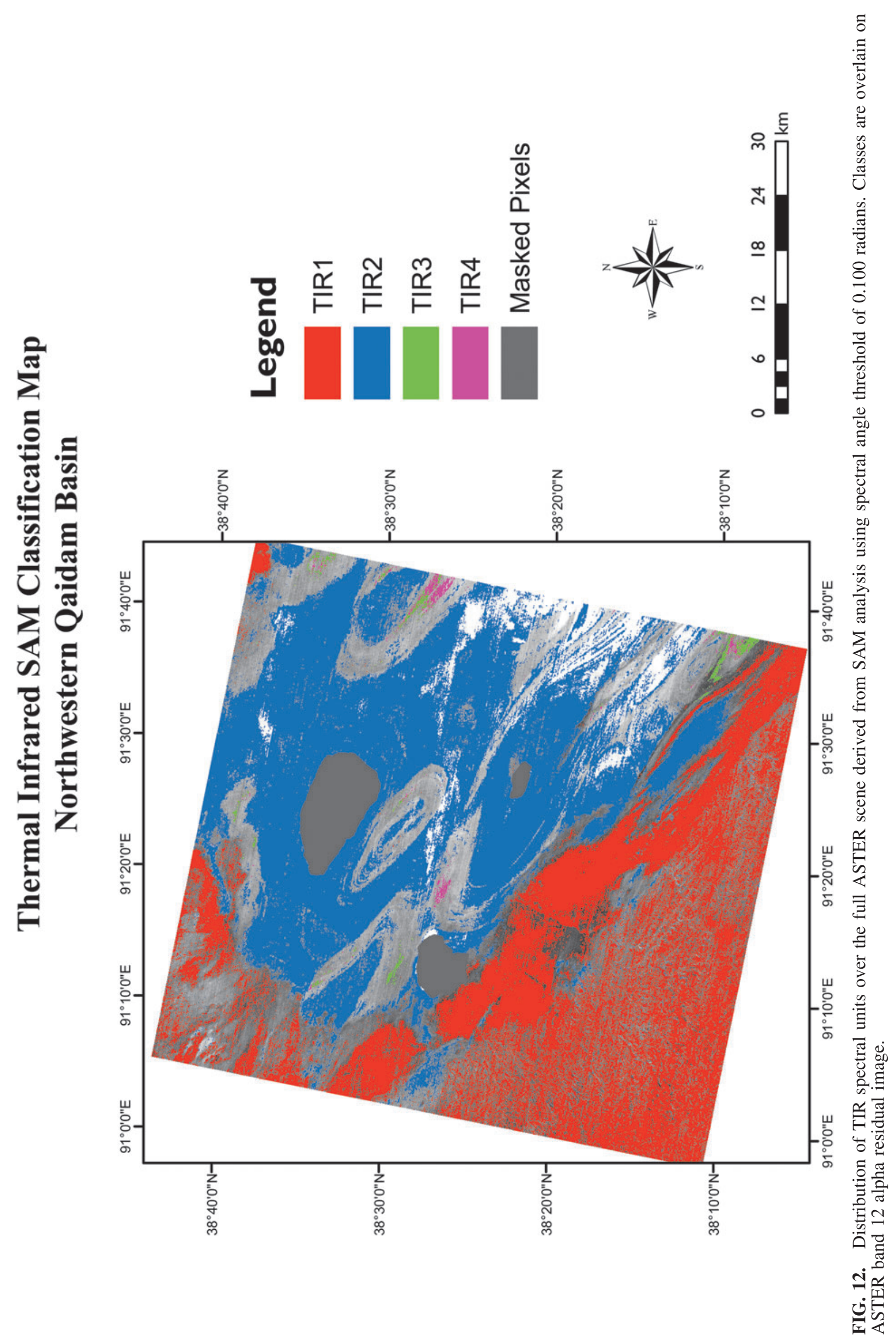


layers near the top of the anticline are classified as spectrally most similar to the XLS4 end-member.

Moving progressively outward from the center of the anticline reveals several concentric layers classified as XLS2 units and then another series of concentric XLS4 units. Not all of the units appear continuously around the anticline. Most of the pixels on the southeastern edge of the anticline were not classified, possibly because they are composed of mixtures of several of the end-members. Pixels mapped as spectrally similar to XLS3 occur in two distinct layers exposed on the northwestern half of XLS as well as the basin floor surrounding the anticline. Except for a few pixels in a layer near the top of the anticline, unit XLS1 appears only in very narrow layers on the northwestern slope of the anticline. The discontinuous nature of the mapped units may be due, in part, to the asymmetry of the anticline.

The southwestern limb of XLS has a much steeper slope than that on the opposite limb, causing shortening and apparent pinching out of layers that are more readily visible on shallower slopes.

Figure 12 shows the SAM classification map of the four TIR spectral end-members. The TIR1 and TIR2 spectral units dominate the map. The TIR1 spectral unit characterizes the surface of Yushashan and the basin floor between Yushashan and Nanyishan as well as much of the scree slope in front of the Altun Mountains in the northwestern corner of the image. This distribution of the TIR1 unit is consistent with the interpretation that the TIR1 end-member spectrum represents quartz and/or other felsic minerals. The portion of the Altun Mountains outside of the image to the northwest is composed primarily of granitic rocks (Liu et al., 2009), therefore, colluvium from the mountains would be expected to have a felsic composition. It is, therefore, reasonable to assume that the dunes present in the type location for the TIR1 unit are composed primarily of quartz.

It is interesting to note that this felsic alluvium and colluvium have apparently not penetrated deeply into the basin because much of the rest of the basin floor is dominated by the TIR2 unit. As discussed earlier, the TIR2 unit is inter- preted to consist primarily of halite. The distribution of TIR3 and TIR4 units appears limited to small exposures on the limbs of anticlinal domes in the scene, concentric about the TIR2 material.

\subsection{In situ reflectance spectroscopy}

We recorded NIR reflectance spectra at each of the sampling sites along the traverse route shown in Figure 3 using the WIR instrument, without any sample preparation. Figure 13 shows selected spectra from surface materials in the anticline. The spectra are offset for visualization purposes. All NIR spectra are dominated by strong water combination bands near 1.45 and $1.95 \mu \mathrm{m}$ and a weak band near $1.76 \mu \mathrm{m}$, which is consistent with gypsum (Bishop et al., 2004). Owing to the limited spectral resolution of the WIR instrument and the high absorption of water units in our spectral range, we were not able to confirm the presence of other minerals in the spectra unambiguously. We are currently exploring linear and nonlinear spectral unmixing techniques to mitigate these challenges and improve mineral identification in complex mixtures (Sobron et al., 2013b).

\subsection{Laboratory analyses}

4.3.1. VNIR reflectance (VNIR spectroscopy). We obtained VNIR reflectance spectra of 14 surface samples collected along the traverse (Fig. 3) in the laboratory using an ASD FieldSpec Pro reflectance spectrometer. The spectra of the samples are shown in Figure 14. The laboratory spectra feature higher spectral resolution and signal-to-noise ratio (SNR) than those recorded in the field. The laboratory reflectance spectra of all the samples contain a shallow absorption feature near $0.83 \mu \mathrm{m}$, which is associated with an $\mathrm{Fe}^{3+}$ spin-forbidden band (Crowley et al., 2006). The laboratory reflectance spectra of 11 of the 14 samples contain an absorption triplet centered near $1.5 \mu \mathrm{m}$ that is diagnostic of gypsum. The identification of gypsum is further confirmed by the presence of an absorption centered near $1.7 \mu \mathrm{m}$ and an absorption doublet with minima located at 2.21 and $2.26 \mu \mathrm{m}$.

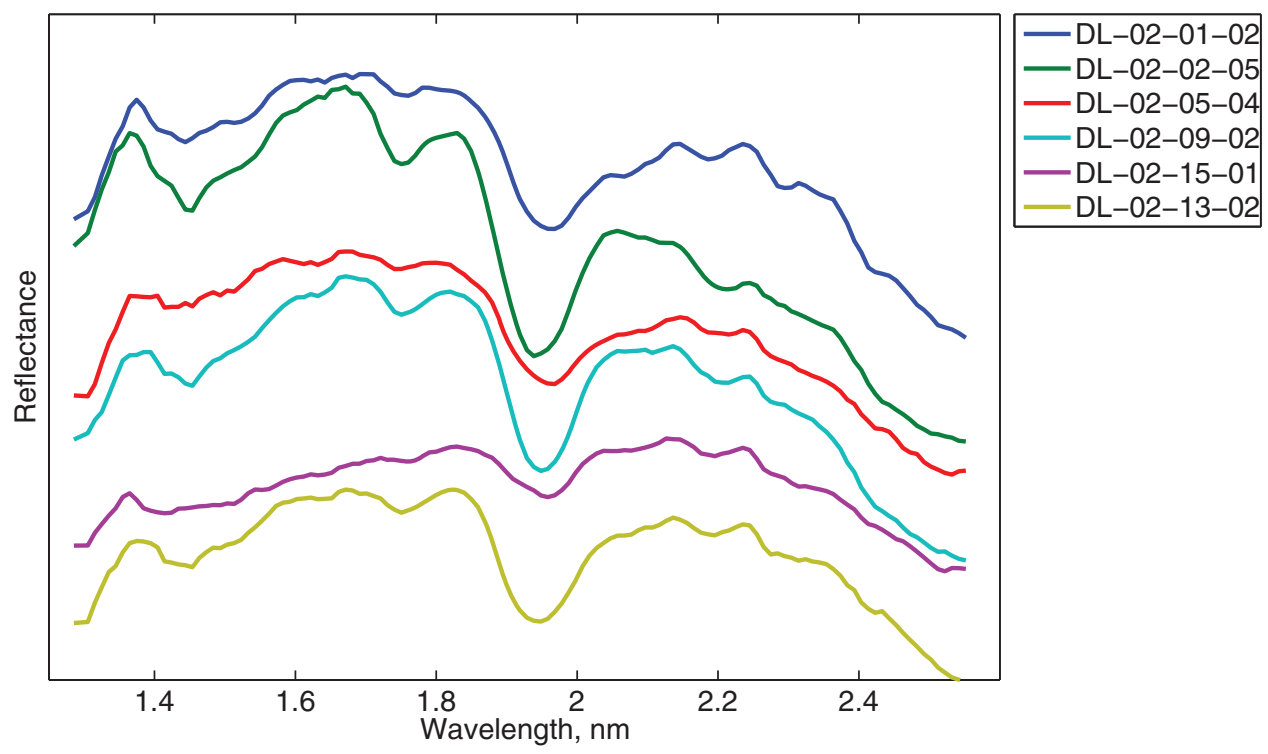

FIG. 13. NIR spectra of select location along the anticline traverse recorded in the field using the WIR spectrometer. Gypsum features at $1.7,2.21$, and $2.26 \mu \mathrm{m}$ dominate the spectra. 


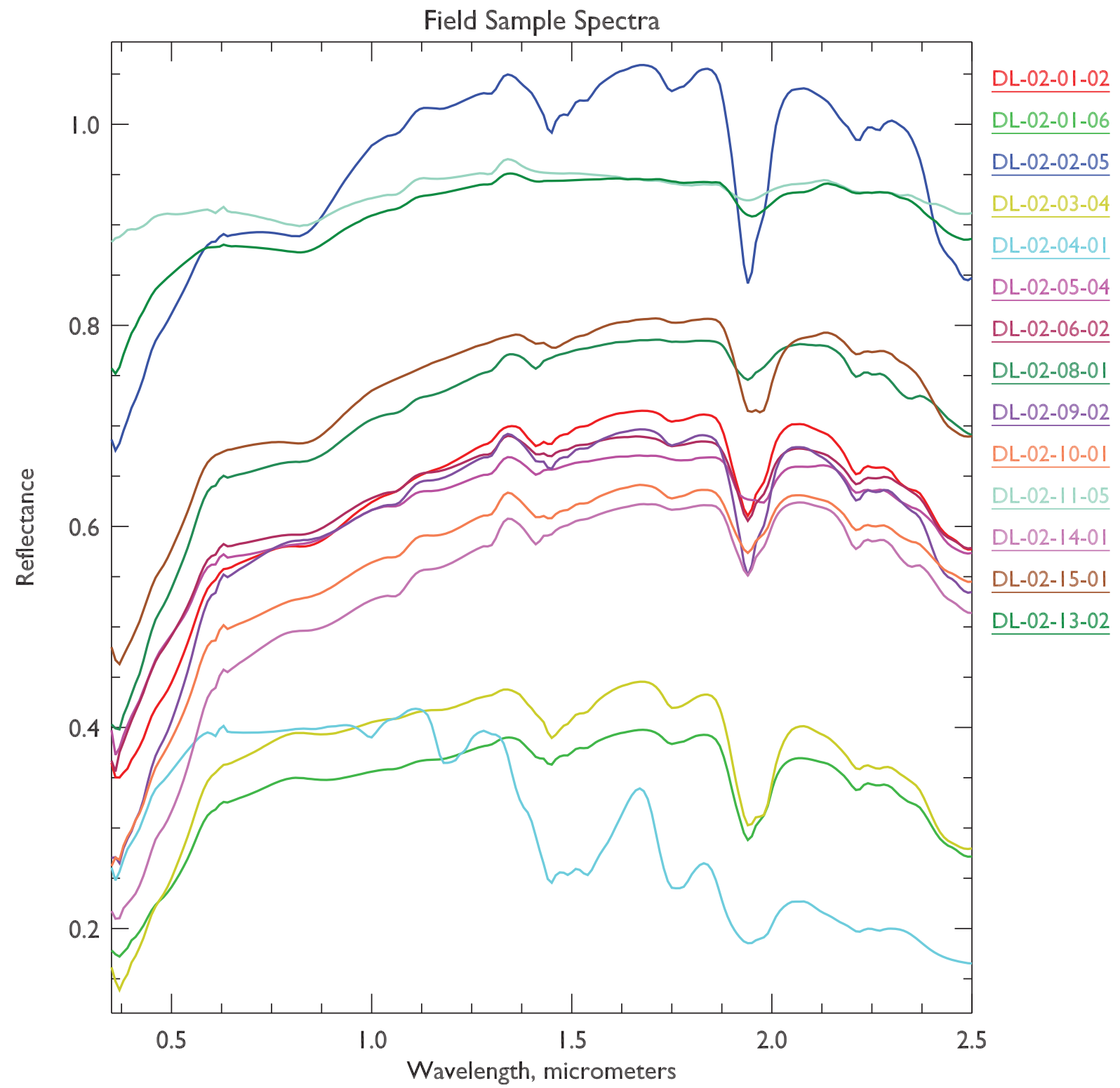

FIG. 14. VNIR laboratory spectra of samples collected along the traverse recorded with the ASD spectrometer. Sample locations shown in Figure 3.

Table 4. Mineral Interpretation of Field Samples Based on Laboratory Reflectance Spectra

\begin{tabular}{lc}
\hline Sample ID & Laboratory VNIR result \\
\hline DL-02-01-02 & Gypsum, illite \\
DL-02-01-06 & Gypsum, illite \\
DL-02-02-05 & Gypsum, illite \\
DL-02-03-04 & Gypsum, illite \\
DL-02-04-01 & Gypsum \\
DL-02-05-04 & Gypsum, illite \\
DL-02-06-02 & Gypsum, illite \\
DL-02-08-01 & Illite, calcite (?) \\
DL-02-09-02 & Gypsum, illite \\
DL-02-10-01 & Gypsum, illite \\
DL-02-11-05 & Thenardite (?) \\
DL-02-13-02 & Thenardite (?) \\
DL-02-14-01 & Gypsum, illite \\
DL-02-15-01 & Gypsum, illite
\end{tabular}

$?=$ tentative.
The absorption triplet between 1.4 and $1.6 \mu \mathrm{m}$ is associated with overtones of the $\mathrm{OH}$ fundamental stretching mode (Crowley, 1991; Crowley and Hook, 1996). The absorption near $1.7 \mu \mathrm{m}$ is associated with a combination of $\mathrm{H}_{2} \mathrm{O}$ bending mode and $\mathrm{OH}$ fundamental stretch as well as low frequency libration modes of structural water (Crowley, 1991). The absorptions near $2.2 \mu \mathrm{m}$ are associated with a combination of the fundamental $\mathrm{OH}$ stretch and the first overtone of the water libration mode (Crowley and Hook, 1996).

The interpreted mineralogy of the 14 samples, as determined from laboratory reflectance spectroscopy, is listed in Table 4. Similar to in situ spectra, strong gypsum absorption features dominate most laboratory reflectance spectra. This makes it difficult to identify other minerals that may be present in a given sample. However, removing the continuum from the sample spectra reveals a weak absorption feature centered near $2.3 \mu \mathrm{m}$ that closely resembles the $\mathrm{Mg}-\mathrm{OH}$ combination band in illite or a $\mathrm{CO}$ bending mode in calcite. We deduce that this 
feature is indicative of illite rather than calcite because there is an absorption feature at $1.4 \mu \mathrm{m}$ in the spectra that show absorption at $2.3 \mu \mathrm{m}$. The $1.4 \mu \mathrm{m}$ absorption is caused by the first overtones of an $\mathrm{OH}$ stretching mode in illite (Clark, 1999).

Calcite does not contain hydroxyl groups and, therefore, should not show an absorption in its reflectance spectra at $1.4 \mu \mathrm{m}$. However, calcite cannot be ruled out as a minor constituent of samples that contain the $2.3 \mu \mathrm{m}$ feature. Similarly, we cannot rule out the possibility from reflectance spectra alone that the $2.3 \mu \mathrm{m}$ feature is due to $\mathrm{Mg}-\mathrm{OH}$ stretching modes in $\mathrm{Mg}$ phyllosilicates such as saponite, serpentine, or talc, but we think that these minerals are unlikely to be present given the absence of other evidence in the field for hydrothermal alteration or contact metamorphism in the sampled outcrops.

Three of the samples do not show absorption features that are diagnostic of gypsum: sample DL-02-08-01 contains absorption features at 1.4 and $2.3 \mu \mathrm{m}$ that are consistent with illite or a mixture of illite and calcite. DL-02-03-04 and DL02-13-02 appear nearly spectrally featureless except for a broad shallow absorption near $1.9 \mu \mathrm{m}$, consistent with adsorbed water. The reflectance spectra alone of these two samples are insufficient to confidently identify their mineralogy. The two samples appear brilliantly white with a loose fine powdery texture. Their spectra indicate that both samples are anhydrous, but despite their close spatial association with gypsum in the field, their color and texture are inconsistent with the anhydrous form of gypsum, anhydrite.

Halite is also spectrally featureless and often shows a $1.9 \mu \mathrm{m}$ adsorbed water feature but naturally occurring halite would not be expected to have such a loose texture and fine grain size. After ruling out anhydrite and halite, we tentatively interpret these two samples to be predominantly thenardite $\left(\mathrm{Na}_{2} \mathrm{SO}_{4}\right)$ based on the combination of their bright white color, relatively featureless spectra loose powdery occurrence in hand sample. The presence of gypsum and possibly other sulfates is confirmed by our Raman analyses (see section 4.3.2.).

4.3.2. Raman spectroscopy. We recorded Raman spectra from returned samples using a benchtop $532 \mathrm{~nm}$ laser Raman spectrometer. In contrast to the large field of view of both field and laboratory reflectance spectrometers $(\sim 1 \mathrm{~cm})$, the Raman spectrometer we used in the laboratory analyzes relative small targets ( $\sim 6 \mu \mathrm{m}$ in diameter). Therefore, singlespot Raman spectra from our field samples may not be representative of the composition of the sample as a whole because those are mixtures of several mineral phases and are heterogeneous on length scales much greater than the size of our focused laser spot. This feature of Raman microscopy is valuable for characterizing the microstructure of the sample and facilitates identifying individual components in complex mixtures.

However, in the context of our investigation, we wanted to generate bulk data comparable with that of the reflectance spectrometers. To this end, we used a motorized positioning stage to perform line scans; the stage repositions the field samples automatically along one axis at selected intervals. For each sample, we performed about 30-point scans spaced at $100 \mu \mathrm{m}$. Our approach takes advantage of the Raman microscope system, designed primarily for obtaining high SNR and highly spatially resolved spectra, and provides useful data for the detection of major, minor, and sometimes trace mineral phases. This approach can help interpret the mineralogy of the samples at a bulk scale, and makes the spectra comparable with a macro situation (e.g., XRD and VNIR).

A limitation of our line scan technique is that the focal distance cannot be optimized for each individual spot, and some spectra may feature lower SNR than single-spot Raman analyses.

Figure 15 displays selected laboratory Raman spectra from the field samples. Here we are plotting representative spectra selected among the $>500$ spectra we obtained. For visualization purposes, we show spectra featuring single mineral species, although in most cases the spectra contained complex combinations of bands arising from multiple minerals. Our interpretation of the mineralogy of the field samples is based on direct comparison with Raman spectra from our extensive collection of reference salts (Wang et al. 2009, 2010b, 2011; Ling and Wang, 2010; Kong et al. 2011; Sobron and Wang, 2012; and Wang et al. accompanying article in this issue) and dedicated analysis of Raman band positions and shapes, as discussed in Sobron et al. (2008).

Here we discuss the interpretation of Raman bands arising from sulfates, carbonates, illite, and quartz, the predominant

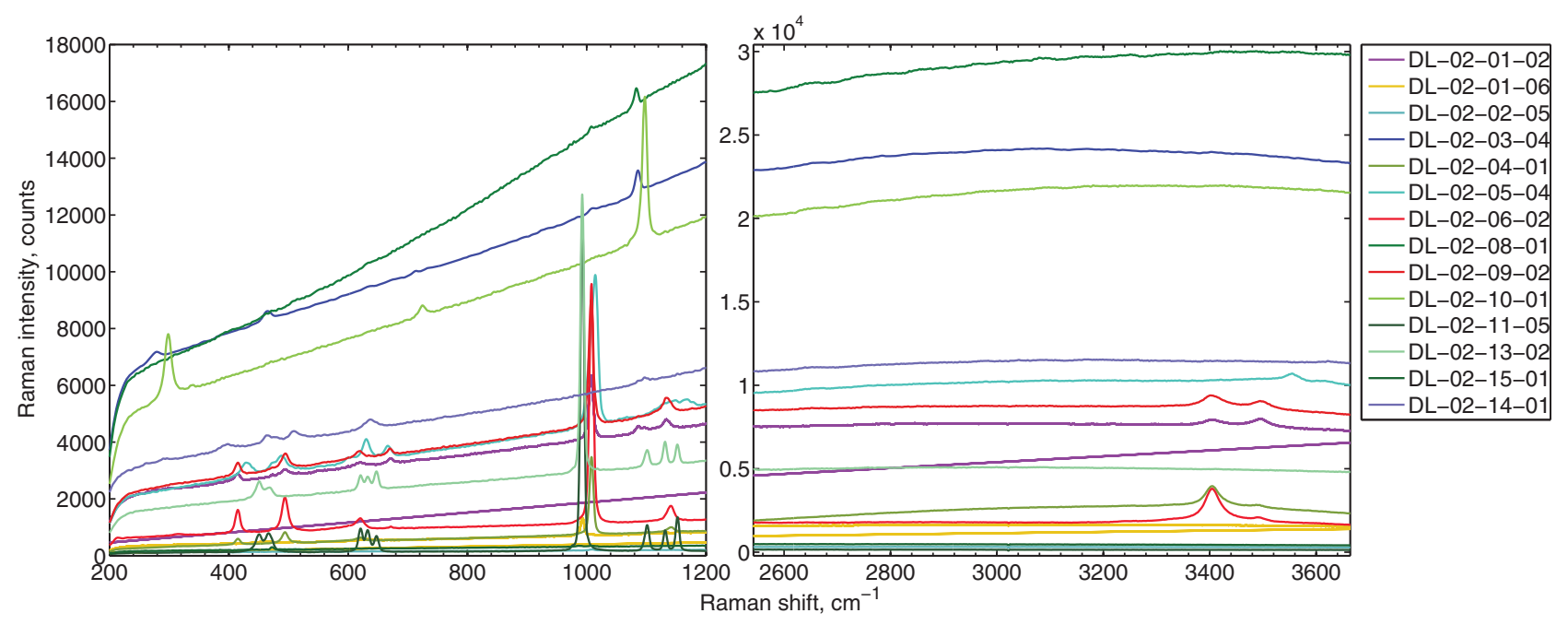

FIG. 15. Raman laboratory spectra of samples collected along the Xiaoliangshan traverse. Sample locations are shown in Figure 3. 
species in our field samples. We also found evidence of anatase $\mathrm{TiO}_{2}$, carbon, feldspar, and many other sulfates and carbonates not currently included in our database. However, we either identified them in very few spectra $(<25)$ or their bands were too weak to warrant discussion. Likewise, we do not report on the presence of halite, an ubiquitous material in DLT, because it is optically transparent to Raman spectroscopy.

Although Raman spectroscopy can be used to identify and analyze halides through $\mathrm{OH}-\mathrm{Cl}$ vibrational modes (Fontana et al., 1977; Desbat and Huong, 1979; Underhill, 1979; Furić et al., 2000; Frost et al., 2002; Frost, 2004), hydrous chlorides are not stable in the hyperarid surface conditions on XLS. Note that we identified these in DLT subsurface samples (see Wang et al., 2018, this volume).

All of the Raman spectra from our XLS samples show bands arising from sulfate molecular vibrations and water. The sets of bands centered around 450 and $600 \mathrm{~cm}^{-1}$ arise from the $v_{2}$ and $v_{4}$ vibrational modes of sulfate tetrahedral oxyanions, respectively (Sobron and Alpers, 2013). The number of bands and position in the $400-500 \mathrm{~cm}^{-1}$ range is indicative of site symmetry in sulfate molecules. Multiple bands in the $v_{2}$ spectral region indicate certain symmetry breakdown of sulfate tetrahedra, probably through the presence of different cations in the crystal structures. Two intense bands are consistent with a better-preserved symmetry. A single sharp band is typical of monocationic $\mathrm{MSO}_{4}$ ( $\mathrm{M}$ denotes a cation) groups, which present the highest symmetry.

Similar to the $v_{2}$ symmetrical bending vibrations, the $v_{4}$ vibrational modes of sulfate give rise to multiple bands in the Raman spectra centered upon $600 \mathrm{~cm}^{-1}$. These can also be explained in terms of loss of symmetry in the sulfate structures.

Band splitting of the sulfate $v_{1}$ and $v_{3}$ vibrational modes is also noticeable in the $800-1200 \mathrm{~cm}^{-1}$ range of the Raman spectra of sulfates in our field samples. The two sets of bands between 978 and $1076 \mathrm{~cm}^{-1}$ and between 1100 and $1200 \mathrm{~cm}^{-1}$ are assigned to the $v_{1}$ symmetric stretching vibrations and $v_{3}$ asymmetric stretching vibrations of $\mathrm{SO}_{4}$ ions, respectively. The Raman shift of the $v_{1} \mathrm{SO}_{4}$ stretching mode depends on the ionic radius of the cation bonded to the sulfate ion (Sobron and Alpers, 2013, and references therein).

Most Raman spectra show a sharp band at $1008 \mathrm{~cm}^{-1}$, which is consistent with gypsum in evaporitic settings (Sobron et al., 2009). In some spectra, the $\mathrm{SO}_{4} v_{1}$ band is shifted toward the blue, at $992 \mathrm{~cm}^{-1}$, thus indicating smaller mass and ionic radius of the bonded cation. We assign this band to thenardite $\left(\mathrm{Na}_{2} \mathrm{SO}_{4}\right)$, a dehydrated form of sodium sulfate typically found in hyperarid environments that give rise to sulfate peaks similar to those we observe in the XLS anticline (Vítek et al., 2010). We observed an upshift $\left(1008-1015 \mathrm{~cm}^{-1}\right)$ of the $\mathrm{SO}_{4} \mathrm{v}_{1}$ band position in several Raman spectra as hydration, and, therefore, site symmetry, decreases (Chio et al., 2004). These spectra are assigned to anhydrite, a dehydrated form of calcium sulfate, also ubiquitous in hyperarid settings.

Gypsum-bearing samples show Raman $\mathrm{OH}$ stretching bands of water units in the $3300-3500 \mathrm{~cm}^{-1}$ range. The sharpness of the water bands varies across samples. This indicates differences in the orientation of the crystal lattice (and optical properties of the crystal) and suggests the presence of local impurities or irregularities in the crystal structure and/or different degree of crystallization (Rull et al., 2011).
We identified calcite $\left(\mathrm{CaCO}_{3}\right)$, dolomite $\mathrm{CaMg}\left(\mathrm{CO}_{3}\right)_{2}$, and magnesite $\left(\mathrm{MgCO}_{3}\right)$ in field samples 02-01-02, 02-0106, 02-03-04, 02-04-01, 02-06-02, 02-08-01, 02-09-02, and 02-14-01 through analysis of bands at 1085 and $1097 \mathrm{~cm}^{-1}$, respectively, which correspond to the symmetric stretching vibration of the carbonate group (Gunasekaran et al., 2006). These spectra also show in-plane carbonate bending vibrations at $\sim 725 \mathrm{~cm}^{-1}$ and librations at $\sim 300 \mathrm{~cm}^{-1}$, although these bands are relatively much weaker.

We also identified illite, a clay mica, in several spectra. Clay minerals are notoriously difficult to analyze with Raman spectroscopy (Wang et al., 2015).

Clays (1) are very weak Raman scatterers because the very small grains $(<2 \mu \mathrm{m}$ across) generate very intense scattering of the laser at the grain interfaces, which reduces the overall amount to Raman scattered photons returning to the collection optics; (2) have very low crystallinity, which dramatically reduces the long-range translational symmetry in the structure and suppresses Raman signal; and (3) typically display a very intense fluorescence background, due to contamination from biogenetic species, that overwhelms the Raman emission and complicates detection. However, owing to the small laser spot size of our Raman system, which can target single mineral grains, we were able to detect the presence of illite in several samples through our line-scan approach.

We observed relatively weak bands at $398,463,510$, and $638 \mathrm{~cm}^{-1}$. The band at $638 \mathrm{~cm}^{-1}$ is associated with the symmetric stretching of the $\mathrm{Si}-\mathrm{O}-\mathrm{Si}$ group in the tetrahedral layer, and the bands at 398,463 , and $510 \mathrm{~cm}^{-1}$ can be assigned to internal vibrational modes of the $\mathrm{SiO}_{4}$ tetrahedral units (Furukawa et al., 1981; Moncada and Bodnar, 2012). A note must be made that it is likely that the $463 \mathrm{~cm}^{-1}$ originates from quartz rather than silicate, as we observe this band in multiple spectra, some of which do not feature Si-OSi bands representative of silicate structural units, but just the sharp strong $463 \mathrm{~cm}^{-1}$ band typical of quartz (Kingma and Hemley, 1994).

Table 5 summarizes the mineralogical identification of the 14 field samples from XLS obtained through analysis of $>500$ micro-Raman spectra recorded from the samples. The identification includes a qualitative estimation of the relative abundance of mineral phases based on the number of positive identifications and detections of bands across all the spectra recorded for each individual sample. A note of caution: due to the intrinsic nonlinearity of the Raman effect, the different cross-section (Raman efficiency) of each material, and the presence of unwanted fluorescence background in many spectra, our estimation of the relative abundance of mineral phases is likely biased toward high Raman scatterers (e.g., gypsum and calcite), and may underestimate the presence of other minerals such as clays.

4.3.3. X-ray diffraction/X-ray fluorescence. We obtained bulk XRD patterns of each of the 14 samples returned from the field (Fig. 16). We used XPowder software to automatically process the diffraction data and generate qualitative identifications of crystalline compounds in our samples. Table 6 lists the results of these analyses. Most of the samples appeared to be a mixture of halite, gypsum, and quartz, along with various other minerals and carbonates. Bulk powder XRD from the portable Terra alone allowed for partial identification of the complete mineralogy of each 
MULTISCALE SPECTROSCOPIC STUDY OF HYPERARID PLAYA DEPOSITS

Table 5. Mineral Interpretation of Field Samples Based on Laboratory Raman Spectra

\begin{tabular}{llll}
\hline & & \multicolumn{2}{c}{ Laboratory Raman result } \\
\cline { 2 - 4 } Sample ID & Major & \multicolumn{1}{c}{ Minor } & \multicolumn{1}{c}{ Trace $^{\mathrm{a}}$} \\
\hline DL-02-01-02 & Gypsum & Calcite, magnesite & Quartz, feldspar, anatase, carbon, illite \\
DL-02-01-06 & Thenardite & $\begin{array}{l}\text { Gypsum, calcite } \\
\text { None }\end{array}$ & Quartz, feldspar, magnesite, illite \\
DL-02-02-05 & None & Thenardite, illite \\
DL-02-03-04 & Gypsum & Calcite & Quartz \\
DL-02-04-01 & Gypsum & Calcite, magnesite & Quartz \\
DL-02-05-04 & Anhydrite & Illite & None \\
DL-02-06-02 & Gypsum & Anhydrite, calcite & Quartz \\
DL-02-08-01 & Calcite & Gypsum & None \\
DL-02-09-02 & Gypsum & Calcite, magnesite & Quartz, feldspar \\
DL-02-10-01 & Illite & Gypsum, anhydrite & Thenardite \\
DL-02-11-05 & Thenardite & None & None \\
DL-02-13-02 & Gypsum & Unidentified sulfates & None \\
DL-02-14-01 & Illite & Calcite, magnesite & Gypsum, quartz \\
DL-02-15-01 & Illite & Gypsum & None \\
\hline
\end{tabular}

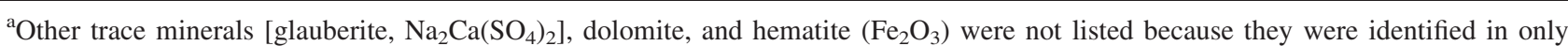
$<10 \%$ of the spectra.

${ }^{\mathrm{b}}$ Spectra are essentially featureless, and thenardite or illite were identified in only $\sim 15 \%$ of the spectra. Major species could be halite, which is featureless in our Raman spectra.

sample, since the highly crystalline phases of halite, gypsum, and quartz dominate the diffractogram and obscure less intense peaks from other clay minerals and evaporates.

Weak peaks were tentatively assigned based on visual inspection of the samples and supporting XRF data. It must be noted that the Terra instrument is limited to elements heavier than Ar, and the relative proportions of the elements present can be misleading. For example, a sample of quartz with slight impurities of $\mathrm{Fe}$ present would have a diffractogram dominated by quartz and XRF data dominated by $\mathrm{Fe}$. In contrast, the presence of $\mathrm{Cl}$ in the XRF data always corresponded to the presence of halite in the XRD data.
Although the less crystalline minerals and evaporates could not be accurately identified, the noisier samples were usually composite mixes of less crystalline minerals that could not be separated before analysis, whereas the pure samples generated clean distinct peaks in the diffractograms. Despite not being able to fully characterize the mineralogy of every sample using bulk powder XRD, the presence and level of noise in the diffractograms could be used as a proxy for identifying a complex and variable sample that requires further analysis, or a sample that formed under environmental conditions less conducive to forming highly crystalline pure minerals.

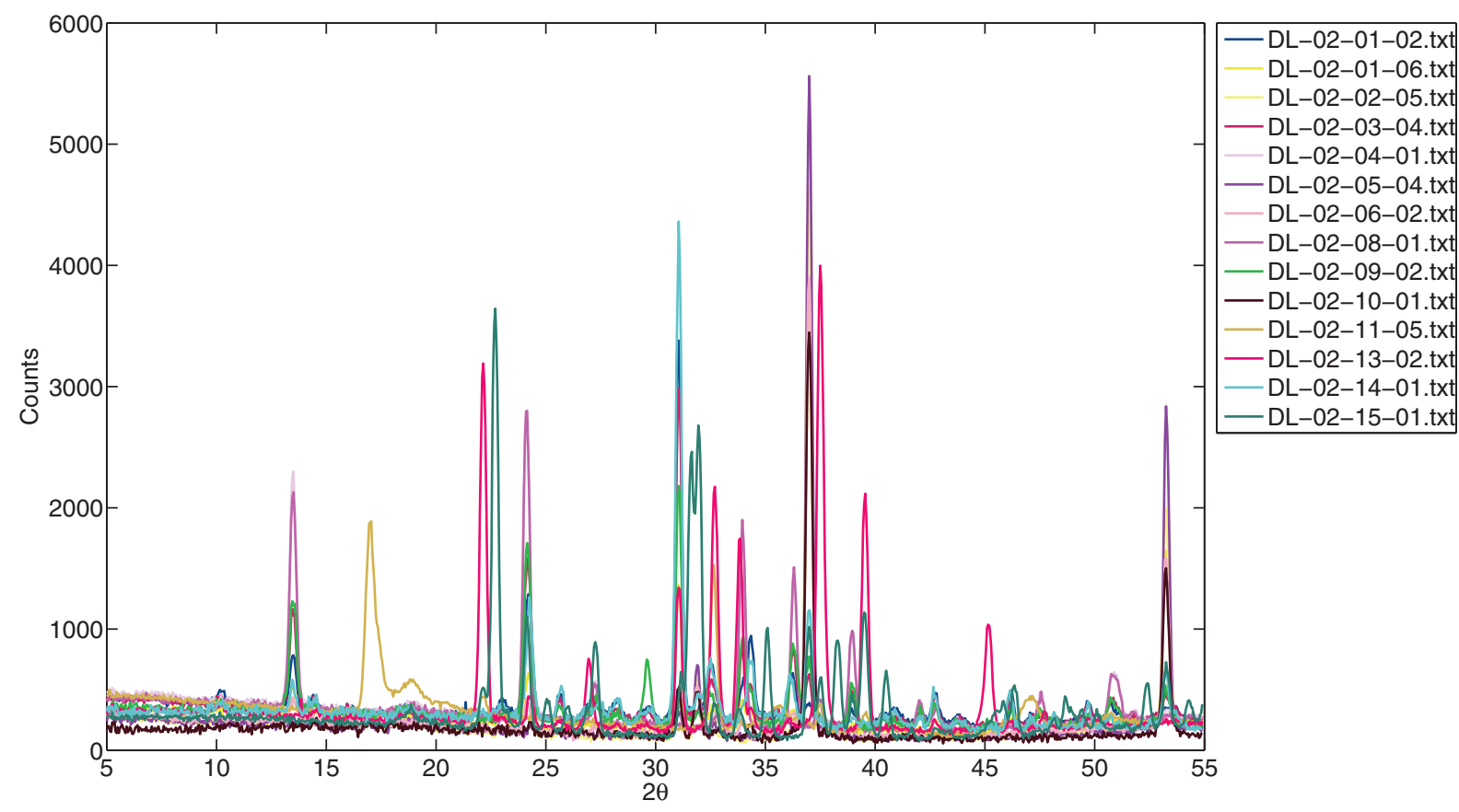

FIG. 16. XRD patterns of samples collected along the Xiaoliangshan traverse. Sample locations are shown in Figure 3. XRD, X-ray diffraction. 
Table 6. Mineral Interpretation of Field Samples Based on Laboratory X-Ray Diffraction Patterns

\begin{tabular}{lll}
\hline & & \multicolumn{1}{c}{ Laboratory XRD/XRF result $^{\mathrm{a}}$} \\
\cline { 2 - 3 } Sample ID & \multicolumn{1}{c}{ Positive identification } & \multicolumn{1}{c}{ Possible identification } \\
\hline DL-02-01-02 & Gypsum, quartz, albite & Anhydrite, polyhalite, calcite, magnesite, unidentified clay \\
DL-02-01-06 & Halite, gypsum, quartz & Muscovite, albite, calcite \\
DL-02-02-05 & Halite, gypsum & None \\
DL-02-03-04 & Gypsum, quartz & Polyhalite \\
DL-02-04-01 & Gypsum & None \\
DL-02-05-04 & Gypsum & Unidentified clay \\
DL-02-06-02 & Gypsum & Calcite, magnesite \\
DL-02-08-01 & Gypsum, quartz & Calcite, muscovite, titanite \\
DL-02-09-02 & Gypsum, halite, quartz & Fe clays \\
DL-02-10-01 & None & Unidentified clay \\
DL-02-11-05 & Polyhalite, thenardite & Anhydrite \\
DL-02-13-02 & Gypsum & Unidentified clay \\
DL-02-14-01 & Gypsum, halite, thenardite & Albite, starkeyite, unidentified clay minerals \\
DL-02-15-01 & Bloedite, thenardite & Epsomite, quartz, starkeyite, halite, albite \\
\hline
\end{tabular}

${ }^{a}$ Albite: $\mathrm{Na}\left(\mathrm{AlSi}_{3} \mathrm{O}_{8}\right)$; polyhalite: $\mathrm{K}_{2} \mathrm{Ca}_{2} \mathrm{Mg}\left(\mathrm{SO}_{4}\right)_{4} \cdot 2 \mathrm{H}_{2} \mathrm{O}$; muscovite: $\mathrm{KAl}_{2}(\mathrm{~F}, \mathrm{OH})_{2}$, or $\left(\mathrm{KF}_{2}\left(\mathrm{Al}_{2} \mathrm{O}_{3}\right)_{3}\left(\mathrm{SiO}_{2}\right)_{6}\right.$; titanite: CaTiSiO 5 ; starkeyite: $\mathrm{MgSO}_{4} \bullet 4 \mathrm{H}_{2} \mathrm{O}$; epsomite: $\mathrm{MgSO}_{4} \bullet 7 \mathrm{H}_{2} \mathrm{O}$

$\mathrm{XRD}=\mathrm{X}$-ray diffraction; $\mathrm{XRF}=\mathrm{X}$-ray fluorescence.

4.3.4. Laser-induced breakdown spectroscopy. We recorded LIBS spectra from returned samples using a benchtop LIBS system. We preprocessed all the spectra following the procedure described by Sobron et al. (2013a). The preprocessing routines include subtraction of continuum background, normalization to the total emission integrated intensity area of each spectrum, and spectra averaging. The preprocessed LIBS spectra of the fourteen samples are shown in Figure 17.

We used a semiquantitative approach for deriving variations in elements concentrations along the anticline traverse. There is a proportional relationship between the intensity of the emission lines of an element in an LIBS spectrum and the concentration of this element in a sample (Cremers and Radziemski, 2006; Miziolek et al., 2006). Our analytical approach computes the relative intensities of the emission lines associated with elements of interest. We define line intensity as the total counts within full width at half maximum. The LIBS spectra of the anticline samples were normalized to the emission integrated total area, so the plots shown in Figure 17 can be used to evaluate variations in the relative concentration of each element as a function of distance from the top of the anticline, from older to younger materials. Using this information, we derived a semiquantitative multielement chemical profile of the anticline, as shown in Figure 18.

We stress the fact that the plots in both figures can only be used for qualitative assessment of changes in the chemical composition of the surface materials in the anticline as a
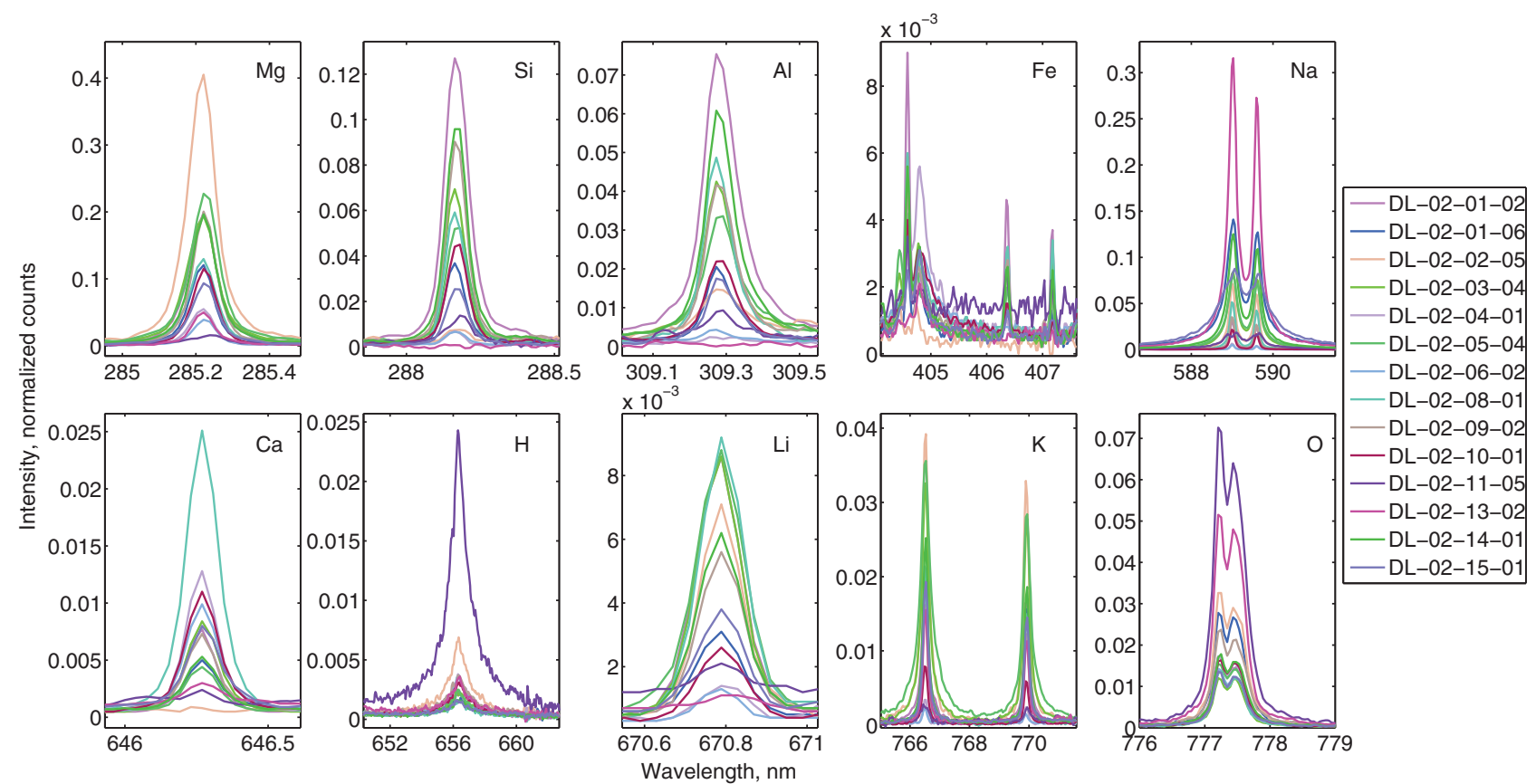

FIG. 17. LIBS spectra of the field samples in selected regions of interest. The spectra were normalized to the total emission area. Sample locations are shown in Figure 3. LIBS, laser-induced breakdown spectroscopy. 


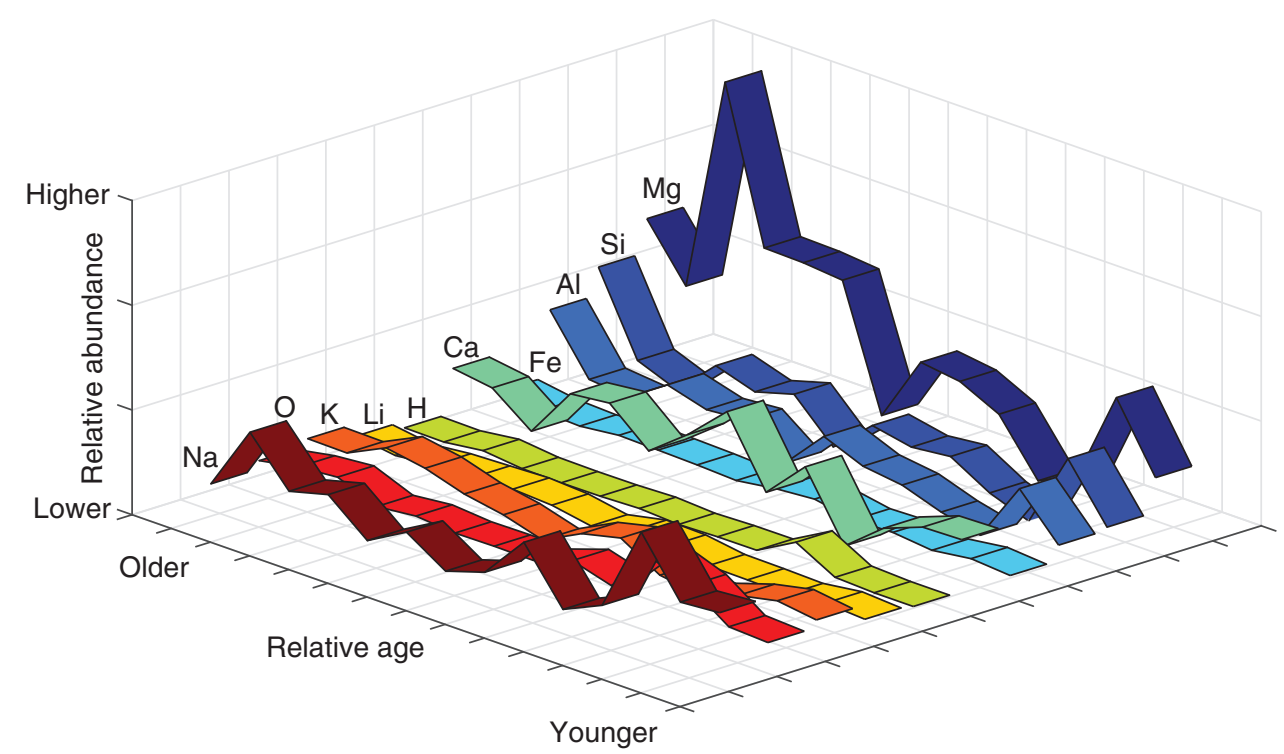

FIG. 18. Chemical profiles of the Xiaoliangshan anticline. The $z$ axis represents the averaged derived line intensity of the emission lines associated with each element for each sample. Younger materials (late Pleistocene) are located in lower elevations and older materials (Paleocene) are associated with higher elevations.

function of distance from the top, which correlates with the age of the deposits-younger materials are located in lower elevations and older materials are associated with higher elevations. Table 7 lists the specific lines used in our analysis and the line intensities for each of the samples in the anticline.

We considered several factors when selecting elements of interest and specific emission lines: relative strength, lack of self-absorption, lack of overlapping lines from other elements, and mineralogical results from the other techniques utilized in this investigation. Although sulfur and chlorine are present in all our samples in the form of halides and sulfates, we were not able to analyze them with our LIBS setup.

The detection of both elements is often a very challenging task in LIBS because (1) the strongest $\mathrm{S}$ lines in LIBS emission are found in the vacuum UV $(<200 \mathrm{~nm})$ and the NIR $(>900 \mathrm{~mm}$ ) ranges (Dudragne et al., 1998; Salle et al., 2004), and most LIBS setups, including ChemCam on Curiosity and SuperCam on Mars 2020 Rovers, cover the range between 200 and $900 \mathrm{~nm}$ only; and (2) electronically excited $\mathrm{S}$ and $\mathrm{Cl}$ in the plasma of $\mathrm{S}$ - and $\mathrm{Cl}$-bearing samples readily reacts with oxygen in laboratory atmosphere. This phenomenon results in a very poor SNR of these lines in this UV-NIR spectral range, as we showed in previous articles (Sobron and Wang, 2010, 2011; Sobron et al., 2013a).

\section{Discussion}

In general, an evaporation sequence leading to the mineralogy and chemistry we observe in the XLS anticline materials forms when natural waters evaporate and ion concentration in solution increases. During mineral precipitation, the concentration of dissolved species changes as a result of the evaporation process. In this article, we focus on semiquantitatively assessing the chemical and mineralogical variations along the transect we sampled in the XLS anticlinal dome. We also correlate our laboratory VNIR reflectance,
Raman spectroscopy, XRD/XRF, and LIBS characterizations of returned samples with the distribution of minerals returned from orbital remote sensing.

Although our results could be utilized to develop evaporative thermodynamic models to explain the occurrence of salts and minerals in the XLS anticlinal dome and the DLT region broadly, this effort is beyond the scope of this project.

The anticline is divided into multiple stratigraphic zones (Fig. 3) in which younger facets (late Pleistocene) are located in lower elevations and older facets (Paleocene) are associated with higher elevations.

A typical evaporation sequence leading to playa deposits such as those in XLS is, according to Qi et al. (1993) and Zheng (1997), expected to contain silica $\left(\mathrm{SiO}_{2}\right)$ and $\mathrm{Ca}$ and $\mathrm{Ca}-\mathrm{Mg}$ carbonates (calcite, magnesite). Ca sulfates (gypsum and anhydrite) may follow. After Ca sulfate formation, more soluble salts such as Na sulfates, $\mathrm{Mg}$ sulfates, and mixed cation sulfates (mirabilite $\left[\mathrm{Na}_{2} \mathrm{SO}_{4} \cdot 10 \mathrm{H}_{2} \mathrm{O}\right]$, thenardite, bloedite $\left[\mathrm{Na}_{2} \mathrm{Mg}\left(\mathrm{SO}_{4}\right)_{2} \cdot 4 \mathrm{H}_{2} \mathrm{O}\right]$, epsomite $)$ will form. Halite will precipitate throughout this process, and other chlorides and chloride-sulfates will form as well (Liu et al., 2004).

The detrital portion of the lake sediments is typically dominated by clay minerals, quartz, and feldspars. Our laboratory mineralogical results are consistent with the Qi et al. (1993) and Zheng (1997) observations; we identified all of these phases with one or several techniques. The LIBS-derived chemical profiles add additional geochemical information on the spatial distribution of major chemical elements along our anticline traverse that supports the following mineralogical results.

- There is significant sodium and calcium enrichment in younger (lower elevation) zones relative to older zones (higher elevation). By sample No. 10, (younger lower end of anticline toward the northeast), thenardite and bloedite start to dominate the diffractograms, as do polyhalite/halite, thus indicating a change in the environmental conditions of mineral formation. 


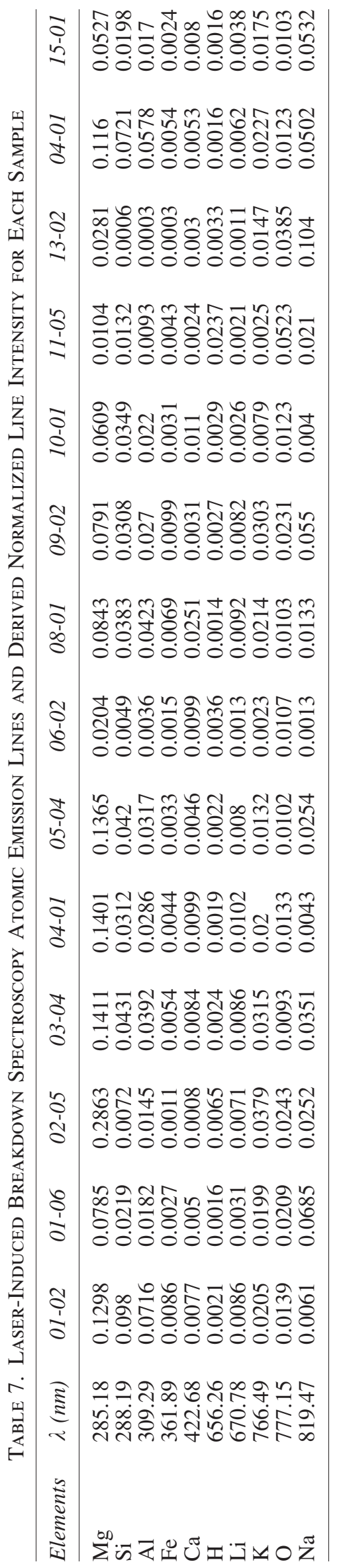

- Younger zones are enriched in hydrogen and oxygen, consistent with the observation of more soluble salts with higher degrees of hydration relative to older zones.

- There is a relatively higher abundance of magnesium in older zones, which likely accounts for the recurrent observation of magnesite in such zones relative to younger zones.

- Iron and lithium abundance is very low across zones, consistent with continental brines not associated with igneous and/or geothermal activity and containing little to no iron remobilized through regolith weathering.

- The relative content of both aluminum and silicon decreases toward younger zones. It is likely that illite, a layered aluminosilicate, is more abundant in such zones relative to older zones, as suggested by our Raman and XRD mineralogical interpretations. The Raman analysis also suggests that quartz is less abundant in younger zones, which could also account for the decrease in silicon relative to older zones.

In summary, the mineralogical and chemical results we obtained from laboratory analyses of returned samples from the XLS anticline support previous research that described mineral distribution and evaporation sequences in the DLT region (Zheng, 1997).

We used these results to constrain the mineralogy of the ASTER-defined VNIR/SWIR spectral units. Harsh terrain, minimal road access, and other logistical constraints limited field observations to a southwest-northeast traverse across the middle of XLS. To relate reflectance spectra of the field samples back to spectral units derived from the ASTER scene, the laboratory reflectance spectra were resampled to the ASTER VNIR/SWIR bandpasses (Fig. 19), and analyzed for their similarity to the spectra of the four spectral endmembers from the XLS subset using a spectral feature-fitting algorithm. This technique determines the least squares fit between absorption features in the laboratory spectra and the reference spectral end-members.

Samples with the strongest absorption features due to gypsum tend to match best with the XLS2 end-member unit, whereas samples with more subtle spectral signatures of gypsum (and relatively stronger spectral signatures of illite) match best with the XLS4 end-member unit. These results are broadly consistent with the SAM classification map of the XLS spatial subset (Fig. 11), which shows that the northeastern limb of XLS only contains material from the XLS2 and XLS4 units. However, the majority of the resampled laboratory spectra appeared to match most closely with the XLS4 spectrum even though many of these samples were collected from areas classified as XLS2 in Figure 11. This discrepancy may be due, in part, to ASTER's low spatial resolution and thus, inability to distinguish subtle spectral differences over distances between sample locations shown in Figure 3.

The thenardite samples do not match any of the spectral end-members, owing to the fact that they are generally featureless in NIR spectra. It is difficult to constrain the mineralogy of the VNIR/SWIR end-member units derived from the full ASTER scene because field samples were only obtained from XLS. However, the mineralogy of spectral units derived from the full scene that appear on XLS in the SAM classification map (Fig. 10) can be inferred from their location with respect to pixels classified 


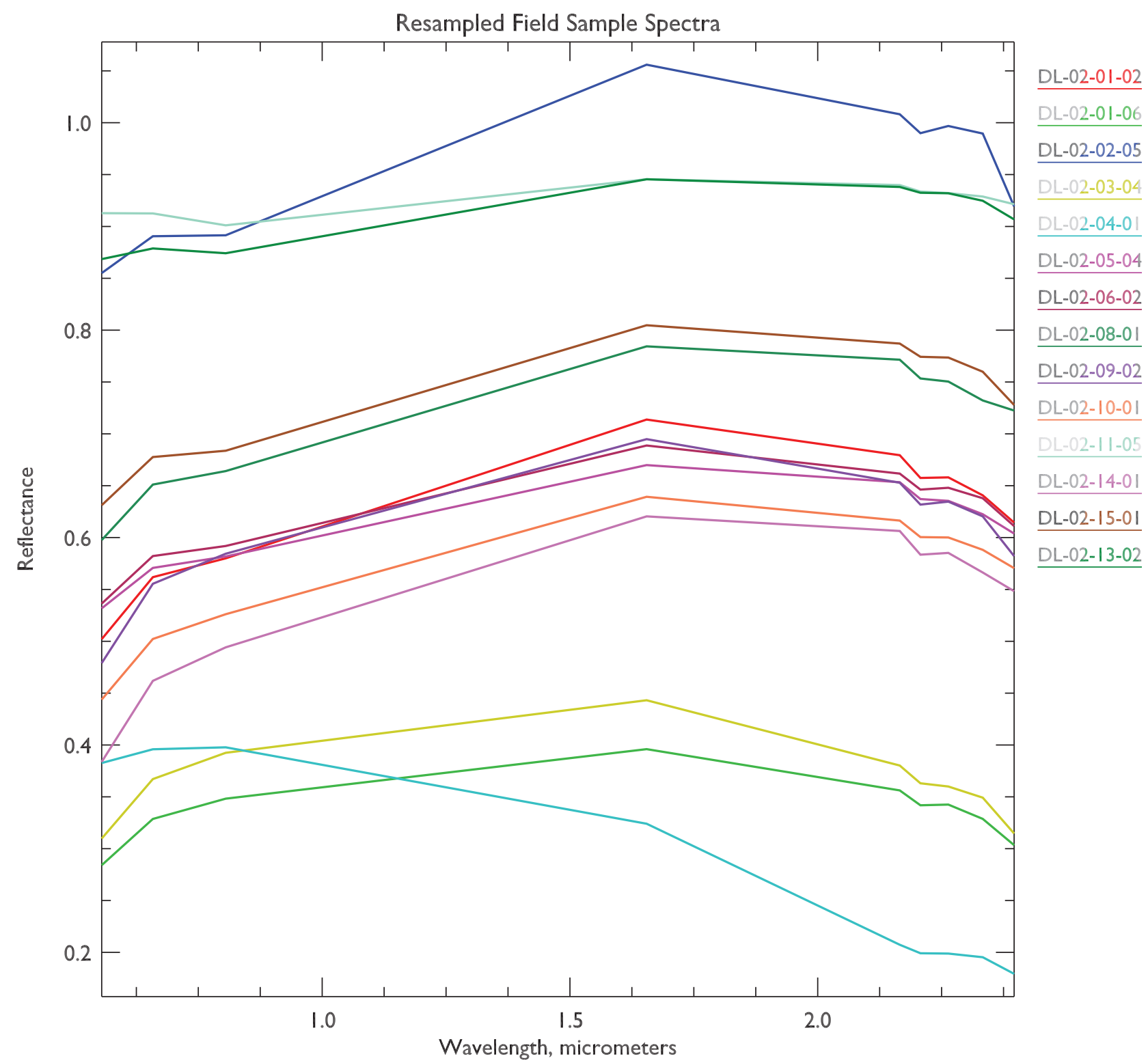

FIG. 19. Laboratory spectra of samples collected along Xiaoliangshan traverse, resampled to ASTER bandpasses.

as XLS2 or XLS4. In particular, spectral unit VFLR2 appears to map to the same layers exposed on XLS as unit XLS2. Unit VXLS1 maps to contacts between XLS2 and XLS4 material, suggesting that it represents a mixture of the two spectral units identified from the XLS subset.

The identification of TIR spectral end-members TIR 1 and TIR2 as representing quartz and halite, respectively, cannot be verified from VNIR/SWIR reflectance spectra alone because these minerals are not active within the VNIR/SWIR wavelength ranges. However, we observed halite on the XRD patterns of samples from near the center of the anticline and on the floor of the basin at the northeastern extent of the traverse, coincident with areas classified as spectrally similar to TIR2 in the TIR SAM classification map. Based on the identification of gypsum in the laboratory with all the techniques we used in this investigation, we argue that the small exposures of TIR3 and TIR4 material on the northeastern limb of XLS are composed of gypsum, in good agreement with the initial designation of TIR3 and TIR4 as sulfates.

\section{Conclusions}

We report the first multiscale systematic field-based testing of correlations between orbital scale and outcrop scale mineralogy and chemistry in a saline dry lakebed. A major difficulty in characterizing these features in XLS is the fact that mineral distribution occurs at all scales. The images we obtained at various scales, from as small as micron scale to as large as remotely sensed information from satellite, demonstrate that we can map these mineral distributions.

Both field and laboratory measurements depend on the field of view (spatial scale) of the instrument used. This (1) explains the inconsistency in the VNIR reflectance, Raman spectroscopy, and XRD mineralogical interpretations; (2) provides a complete picture of the mineralogical composition of the samples; and (3) demonstrates that the three techniques are fully complementary and can be used simultaneously for bridging orbital remote ASTER VNIR/SWIR reflectance and TIR relative emissivity data to some of the fine scale Raman 
spectroscopy, VNIR reflectance, XRD, and LIBS data obtained from field samples.

We have defined spectral end-members in the northwestern Qaidam Basin and classified areas within the study area on the basis of their spectral similarity to the spectral end-members. Results of VNIR/SWIR classification reveal zonation of spectral units within three large anticlinal domes in the study area that can be correlated between the three structures. Laboratory Raman, VNIR reflectance, XRD, and LIBS data of surface mineral samples collected along a traverse over XLS indicate that the surface is dominated by gypsum and $\mathrm{Mg}$ sulfates and $\mathrm{Na}$ sulfates, halite, and carbonates, with minor concentrations of illite present in most samples as well.

Identifying mineral distributions by using satellite imagery typically requires a detailed knowledge of the area of interest before proceeding. Information about the actual minerals present in XLS, corresponding to various periods in the evaporation sequence of the anticline, is commonly termed ground truth. Ground truth helps associate orbital spectral signatures with known minerals and assess how accurately different minerals can be identified in a processed satellite data set. In this application, we collected ground truth by physically traversing the XLS anticline, recording in situ reflectance spectra, and collecting samples for subsequent laboratory analysis.

The laboratory identification of gypsum and magnesium sulfates on XLS supports the interpretation that two of the four TIR end-members represent sulfates. The interpretation of an additional TIR end-member as halite was confirmed by XRD analysis of returned samples from XLS areas that appear in the TIR SAM classification map as belonging to that spectral unit. Although the ASTER data were useful for identifying spectral end-members within the study area, the limited spectral resolution of ASTER's SWIR subsystem makes it difficult to attribute spectral features to specific minerals. Our work shows that fine scale in situ mineralogy and chemistry tools are very useful for ground truthing the mineralogy of spectral units that we mapped remotely, and constraining the likely composition of unresolved spectral units in our remote sensing analysis of XLS.

With sufficient ground truth, it is possible to train a computer-based model to associate spectral signatures with specific minerals (supervised classification), or even program the model to group signatures in an unsupervised way. In this work, we manually assigned specific minerals to specific locations in the anticline by means of dedicated analysis of the VNIR reflectance, Raman, XRD, and LIBS data collected in the laboratory.

Current and upcoming missions to Mars utilize these techniques for in situ rover-based investigations of the martian surface and subsurface. Our results from XLS can be used as a first step toward better characterizing the potential of orbital reflectance spectroscopy as a method for mineral detection and quantification in salt-rich planetary environments, with the benefit that this technique can be validated on the ground by using instruments onboard rovers.

The spectral models we have derived for the XLS anticline provide a foundation for assessing the mineralogy in the DLT region broadly-efforts are currently underway based on the preliminary survey of the full ASTER scene (Fig. 1). Our methodology may be used in future planetary exploration missions that combine remote orbiter-based spectral measurements and close-up, rover, or lander-based investigations.

\section{Acknowledgments}

The authors express their great appreciation to the McDonnell Center for Space Science at Washington University in St. Louis (WUSTL) for its generous financial support to the WUSTL team's (A.W., P.S., and D.M.) field expedition to Qaidam Basin on Tibet Plateau in 2008, and its continuous financial support for laboratory sample analysis and article writing. We also thank the invaluable help provided by scientists from R\&D Center of Saline Lakes and Epithermal Deposits, Chinese Academy of Geological Sciences, SUV drivers from Gelmu geological exploration team, and geologists from local mining companies. The NASA Astrobiology Institute supported the role of P.S. as lead author by providing funds to write this article.

\section{Author Disclosure Statement}

No competing financial interests exist.

\section{References}

Anglés, A. and Li, Y. (2017) The western Qaidam Basin as a potential martian environmental analogue: an overview. J Geophys Res Planets 122:856-888.

Ayoub, F., Avouac, J.P., Newman, C.E., Richardson, M.I., Lucas, A., Leprince, S., and Bridges, N.T. (2014) Threshold for sand mobility on Mars calibrated from seasonal variations of sand flux. Nat Commun 5:5096.

Bailey, G.B. and Anderson, P.D. (1982) Application of Landsat imagery to problems of petroleum exploration in Qaidam Basin, China. Am Assoc Pet Geol Bull 66:1348-1354.

Baker, V.R. (2013) Rethinking the Fabric of Geology. Geological Society of America, Washington, DC

Baldridge, A.M., Farmer, J.D., and Moersch, J.E. (2004) Mars remote-sensing analog studies in the Badwater Basin, Death Valley, California. J Geophys Res Planets 109: E12006.

Bandfield, J.L. (2002) Global mineral distributions on Mars. J Geophys Res Planets 107:9-1-9-20.

Bell, J.F., Malin, M., Maki, J., Dietrich, W.E., Edgett, K.S., E, L., Garvin, J.B., Hallet, B., Herkenhoff, K.E., Heydari, E., Johnson, J.R., Kah, L.C., Lemmon, M.T., Minitti, M., Olson, T.S., Parker, T.J., Rice, M.S., Rowland, S.K., Schieber, J., Sletten, R.S., Sullivan, R.J., Sumner, D.Y., Thomas, P.C., and Yingst, R.; Team, M. (2013) Mars Science Laboratory Curiosity rover initial Mastcam geomorphologic and multispectral characterization of the Gale crater field site. In $A G U$ Fall Meeting Abstracts, 14:02.

Berk, A., Anderson, G.P., Bernstein, L.S., Acharya, P.K., Dothe, H., Matthew, M.W., Adler-Golden, S.M., Chetwynd, J.H., Richtsmeier, S.C., Pukall, B., Allred, C.L., Jeong, L.S., and Hoke, M.L. (1999) MODTRAN4 radiative transfer modeling for atmospheric correction. In Proc. SPIE 3756, Optical Spectroscopic Techniques and Instrumentation for Atmospheric and Space Research III, pp 348-353.

Bibring, J.-P., Langevin, Y., Mustard, J.F., Poulet, F., Arvidson, R., Gendrin, A., Gondet, B., Mangold, N., Pinet, P., Forget, F., Berthé, M., Bibring, J.P., Gendrin, A., Gomez, C., Gondet, B., Jouglet, D., Poulet, F., Soufflot, A., Vincendon, M., Combes, M., Drossart, P., Encrenaz, T., Fouchet, T., Merchiorri, R., Belluci, G., Altieri, F., Formisano, V., 
Capaccioni, F., Cerroni, P., Coradini, A., Fonti, S., Korablev, O., Kottsov, V., Ignatiev, N., Moroz, V., Titov, D., Zasova, L., Loiseau, D., Mangold, N., Pinet, P., Douté, S., Schmitt, B., Sotin, C., Hauber, E., Hoffmann, H., Jaumann, R., Keller, U., Arvidson, R., Mustard, J.F., Duxbury, T., Forget, F., and Neukum, G. (2006) Global mineralogical and aqueous mars history derived from OMEGA/Mars Express data. Science 312:400-404.

Bishop, J.L., Darby Dyar, M., Lane, M.D., and Banfield, J.F. (2004) Spectral identification of hydrated sulfates on Mars and comparison with acidic environments on Earth. Int $J$ Astrobiol 3:275-285.

Bishop, J.L., Loizeau, D., McKeown, N.K., Saper, L., Dyar, M.D., Des Marais, D.J., Parente, M., and Murchie, S.L. (2013) What the ancient phyllosilicates at Mawrth Vallis can tell us about possible habitability on early Mars. Planet Space Sci 86:130-149.

Bishop, J.L., Schelble, R.T., McKay, C.P., Brown, A.J., and Perry, K.A. (2011) Carbonate rocks in the Mojave Desert as an analogue for martian carbonates. Int J Astrobiol 10:349-358.

Blake, D., Vaniman, D., Achilles, C., Anderson, R., Bish, D., Bristow, T., Chen, C., Chipera, S., Crisp, J., Des Marais, D., Downs, R.T., Farmer, J., Feldman, S., Fonda, M., Gailhanou, M., Ma, H., Ming, D.W., Morris, R.V., Sarrazin, P., Stolper, E., Treiman, A., and Yen, A. (2012) Characterization and calibration of the CheMin mineralogical instrument on Mars Science Laboratory. Space Sci Rev 170:341-399.

Boardman, J.W., Kruse, F.A., and Green, R.O. (1995) Mapping target signatures via partial unmixing of AVIRIS data. In Fifth JPL Airborne Earth Science Workshop. JPL Publication, Pasadena, CA, Vol. 95, 23-26.

Brown, A., Walter, M., and Cudahy, T. (2004) Short-wave infrared reflectance investigation of sites of paleobiological interest: applications for Mars exploration. Astrobiology 4: 359-376.

Brown, A.J., Hook, S.J., Baldridge, A.M., Crowley, J.K., Bridges, N.T., Thomson, B.J., Marion, G.M., de Souza Filho, C.R., and Bishop, J.L. (2010) Hydrothermal formation of Clay-Carbonate alteration assemblages in the Nili Fossae region of Mars. Earth Planet Sci Lett 297:174-182.

Brown, A.J., Walter, M.R., and Cudahy, T.J. (2005) Hyperspectral imaging spectroscopy of a Mars analogue environment at the North Pole Dome, Pilbara Craton, Western Australia. Aust J Earth Sci 52:353-364.

Chio, C.H., Sharma, S.K., and Muenow, D.W. (2004) MicroRaman studies of gypsum in the temperature range between 9 K and 373 K. Am Mineral 89:390-395.

Christensen, P.R., Bandfield, J.L., Hamilton, V.E., Howard, D.A., Lane, M.D., Piatek, J.L., Ruff, S.W., and Stefanov, W.L. (2000) A thermal emission spectral library of rockforming minerals. J Geophys Res Planets 105:9735-9739.

Christensen, P.R., Wyatt, M.B., Glotch, T.D., Rogers, A.D., Anwar, S., Arvidson, R.E., Bandfield, J.L., Blaney, D.L., Budney, C., Calvin, W.M., Fallacaro, A., Fergason, R.L., Gorelick, N., Graff, T.G., Hamilton, V.E., Hayes, A., Johnson, J.R., Knudson, A., McSween, H.Y., Mehall, G.L., Mehall, L.K., Moersch, J.E., Morris, R.V., Smith, M.D., Squyres, S., Ruff, S., and Wolff, M.J. (2004) Mineralogy at Meridiani Planum from the Mini-TES experiment on the Opportunity rover. Science 306:1733-1739.

Clark, R.N. (1999) Chapter 1: spectroscopy of rocks and minerals, and principles of spectroscopy. In Manual of Remote Sensing, edited by A.N. Renczs, John Wiley and Sons, New York, NY, pp 3-58.
Clarke, J.D.A. and Bourke, M.C. (2011) Travertine and tufa from Dalhousie Springs (Australia)-implications for recognizing martian springs. In Geological Society of America Special Papers [Paper No. 483], pp 231-247.

Cremers, D.A. and Radziemski, L.J. (2006) Handbook of LaserInduced Breakdown Spectroscopy. John Wiley \& Sons, Chichester, West Sussex, England; Hoboken, NJ.

Crowley, J.K. (1991) Visible and near-infrared $(0.4-2.5 \mu \mathrm{m})$ reflectance spectra of Playa evaporite minerals. $J$ Geophys Res Solid Earth 96:16231-16240.

Crowley, J.K. and Hook, S.J. (1996) Mapping playa evaporite minerals and associated sediments in Death Valley, California, with multispectral thermal infrared images. J Geophys Res Solid Earth 101:643-660.

Crowley, J.K., Williams, D.E., Hammarstrom, J.M., Piatak, N., Mars, J.C., and Chou, I.M. (2006) Spectral reflectance properties (0.4-2.5 um) of secondary Fe-oxide, Fe-hydroxide, and Fe-sulfate-hydrate minerals associated with sulfidebearing mine waste. In: Open-File Report 2003-196, U.S. Geological Survey Publications Warehouse, Reston, VA.

Desbat, B. and Huong, P.V. (1979) Determination by Raman spectroscopy of the solvation number of the chloride ion in liquid hydrogen chloride. J Raman Spectrosc 8:177-179.

Dudragne, L., Adam, P., and Amouroux, J. (1998) Timeresolved laser-induced breakdown spectroscopy: application for qualitative and quantitative detection of fluorine, chlorine, sulfur, and carbon in air. Appl Spectrosc 52:1321-1327.

Edgett, K., Yingst, R.A., Ravine, M., Caplinger, M., Maki, J., Ghaemi, F.T., Schaffner, J., Bell, J., III, Edwards, L., Herkenhoff, K., Heydari, E., Kah, L.C., Lemmon, M.T., Minitti, M.E., Olson, T.S., Parker, T.J., Rowland, S.K., Schieber, J., Sullivan, R.J., Sumner, D.Y., Thomas, P.C., Jensen, E.H., Simmonds, J.J., Sengstacken, A.J., Willson, R.G., and Goetz, W. (2012) Curiosity's Mars Hand Lens Imager (MAHLI) investigation. Space Sci Rev 170:259-317.

Ehlmann, B.L., Mustard, J.F., Murchie, S.L., Bibring, J.-P., Meunier, A., Fraeman, A.A., and Langevin, Y. (2011) Subsurface water and clay mineral formation during the early history of Mars. Nature 479:53-60.

Fassett, C.I., Head, J.W., Kadish, S.J., Mazarico, E., Neumann, G.A., Smith, D.E., and Zuber, M.T. (2012) Lunar impact basins: stratigraphy, sequence and ages from superposed impact crater populations measured from Lunar Orbiter Laser Altimeter (LOLA) data. J Geophys Res Planets 117:E00H06.

Fontana, M.P., Viliani, G., Fontana, A., Montagna, M., Capozzi, V., and Mariotto, G. (1977) Raman spectroscopy of thallium chloride in the melting region. Phys Lett A 64:319321.

Frost, R. (2004) Raman spectroscopy of some basic chloride containing minerals of lead and copper. Spectrochim Acta A Mol Spectrosc 60:2071-2077.

Frost, R.L., Martens, W., Kloprogge, J.T., and Williams, P.A. (2002) Raman spectroscopy of the basic copper chloride minerals atacamite and paratacamite: implications for the study of copper, brass and bronze objects of archaeological significance. J Raman Spectrosc 33:801-806.

Furić, K., Ciglenečki, I., and Ćosović, B. (2000) Raman spectroscopic study of sodium chloride water solutions. $J \mathrm{Mol}$ Struct 550-551:225-234.

Furukawa, T., Fox, K.E., and White, W.B. (1981) Raman spectroscopic investigation of the structure of silicate glasses. III. Raman intensities and structural units in sodium silicate glasses. J Chem Phys 75:3226-3237. 
Green, A.A., Berman, M., Switzer, P., and Craig, M.D. (1988) A transformation for ordering multispectral data in terms of image quality with implications for noise removal. IEEE Transact Geosci Remote Sens 26:65-74.

Gunasekaran, S., Anbalagan, G., and Pandi, S. (2006) Raman and infrared spectra of carbonates of calcite structure. $J R a$ man Spectrosc 37:892-899.

Hauber, E., Reiss, D., Ulrich, M., Preusker, F., Trauthan, F., Zanetti, M., Hiesinger, H., Jaumann, R., Johansson, L., Johnsson, A., Olvmo, M., Carlsson, E., Johansson, H., and McDaniel, S. (2011) Periglacial landscapes on Svalbard: terrestrial analogs for cold-climate landforms on Mars. In Geological Society of America Special Papers [Paper No. 483], pp 177-201.

Hook, S.J., Gabell, A.R., Green, A.A., and Kealy, P.S. (1992) A comparison of techniques for extracting emissivity information from thermal infrared data for geologic studies. Remote Sens Environ 42:123-135.

Hu, P., Tian, Q., Guan, Z., and Yan, B. (2007) Estimating hydrocarbon content using hyperspectral remote sensing at Qaidam Basin, China. Geoinformatics 2007. Published in SPIE Proceedings Vol. 6752: Geoinformatics 2007: Remotely Sensed Data and Information, Weimin Ju; Shuhe Zhao, Editor(s), Bellingham, WA.

ISRO. (2015) Mars Orbiter Mission: Payloads. Available online at http://isro.org/pslv-c25-mars-orbiter-mission/payloads (last accessed October 13, 2017).

Kingma, K.J. and Hemley, R.J. (1994) Raman spectroscopic study of microcrystalline silica. Am Mineral 79:269-273.

Klingelhöfer, G., Morris, R.V., Bernhardt, B., Rodionov, D., de Souza, P.A., Squyres, S.W., Foh, J., Kankeleit, E., Bonnes, U., Gellert, R., Schröder, C., Linkin, S., Evlanov, E., Zubkov, B., and Prilutski, O. (2003) Athena MIMOS II Mössbauer spectrometer investigation. J Geophys Res Planets 108:8067.

Kong, F., Zheng, M., Hu, B., Wang, A., Ma, N., and Sobron, P. (2018) DLT saline playa in an hyperarid region on Tibet Plateau-I: evolution and environments. Astrobiology 18:XX: $\mathrm{XX}$.

Kong, W.G., Wang, A., Freeman, J.J., and Sobron, P. (2011) A comprehensive spectroscopic study of synthetic $\mathrm{Fe}^{2+}, \mathrm{Fe}^{3+}$, $\mathrm{Mg}^{2+}$ and $\mathrm{Al}^{3+}$ copiapite by Raman, XRD, LIBS, MIR and vis-NIR. J Raman Spectros 42:1120-1129.

Kounaves, S.P., Hecht, M.H., Kapit, J., Gospodinova, K., DeFlores, L., Quinn, R.C., Boynton, W.V., Clark, B.C., Catling, D.C., Hredzak, P., Ming, D.W., Moore, Q., Shusterman, J., Stroble, S., West, S.J., and Young, S.M.M. (2010) Wet Chemistry experiments on the 2007 Phoenix Mars Scout Lander mission: data analysis and results. J Geophys Res Planets 115:E00E10.

Kruse, F.A., Lefkoff, A.B., Boardman, J.W., Heidebrecht, K.B., Shapiro, A.T., Barloon, P.J., and Goetz, A.F.H. (1993) The spectral image processing system (SIPS) - interactive visualization and analysis of imaging spectrometer data. Remote Sens Environ 44:145-163.

Lane, M.D. (2007) Mid-infrared emission spectroscopy of sulfate and sulfate-bearing minerals. Am Mineral 92:1-18.

Ling, Z.C. and Wang, A. (2010) A systematic spectroscopic study of eight hydrous ferric sulfates relevant to Mars. Icarus 209:422-433.

Liu, D., Fang, X., Gao, J., Wang, Y., Zhang, W., Miao, Y., Liu, Y., and Zhang, Y. (2009) Cenozoic stratigraphy deformation history in the Central and Eastern of Qaidam Basin by the balance section restoration and its implication. Acta Geol Sin Engl Ed 83:359-371.

Liu, X., Cai, K., and Yu, S. (2004) Geochemical simulation of the formation of brine and salt minerals based on Pitzer model in Caka Salt Lake. Sci China Ser D Earth Sci 47:720_726.

McEwen, A.S., Eliason, E.M., Bergstrom, J.W., Bridges, N.T., Hansen, C.J., Delamere, W.A., Grant, J.A., Gulick, V.C., Herkenhoff, K.E., Keszthelyi, L., Kirk, R.L., Mellon, M.T. Squyres, S.W., Thomas, N., and Weitz, C.M. (2007) Mars reconnaissance orbiter's high resolution imaging science experiment (HiRISE). J Geophys Res 112:E05S02.

McGuire, P.C., Arvidson, R.E., Bishop, J.L., Brown, A.J., Cull, S., Green, R.O., Gross, C., Hash, C.D., Hauber, E., Humm, D.C. (2013) Mapping Minerals on Mars with CRISM: Atmospheric and Photometric Correction for MRDR Map Tiles, Version 2, and Comparison to OMEGA. In: Lunar and Planetary Science Conference, Houston, TX, pp 1581.

Michalski, J.R. and Niles, P.B. (2010) Deep crustal carbonate rocks exposed by meteor impact on Mars. Nat Geosci 3:751-755.

Milliken, R.E., Grotzinger, J.P., and Thomson, B.J. (2010) Paleoclimate of Mars as captured by the stratigraphic record in Gale Crater. Geophys Res Lett 37:L04201.

Miziolek, A.W., Palleschi, V., and Schechter, I. (2006) Laserinduced Breakdown Spectroscopy (LIBS): Fundamentals and Applications. Cambridge University Press, Cambridge, UK.

Moncada, D. and Bodnar, R.J. (2012) Gangue mineral textures and fluid inclusion characteristics of the Santa Margarita Vein in the Guanajuato Mining District, Mexico. Cent Eur J Geosci 4:300-309.

Morris, R.V., Agresti, D.G., Lauer, H.V., Newcomb, J.A., Shelfer, T.D., and Murali, A.V. (1989) Evidence for pigmentary hematite on Mars based on optical, magnetic, and Mossbauer studies of superparamagnetic (nanocrystalline) hematite. J Geophys Res Solid Earth 94:2760-2778.

Morris, R.V. and Lauer, H.V. (1990) Matrix effects for reflectivity spectra of dispersed nanophase (superparamagnetic) hematite with application to martian spectral data. J Geophys Res Solid Earth 95:5101-5109.

Morris, R.V., Lauer, H.V., Lawson, C.A., Gibson, E.K., Nace, G.A., and Stewart, C. (1985) Spectral and other physicochemical properties of submicron powders of hematite $(\alpha-$ $\left.\mathrm{Fe}_{2} \mathrm{O}_{3}\right)$, maghemite $\left(\gamma-\mathrm{Fe}_{2} \mathrm{O}_{3}\right)$, magnetite $\left(\mathrm{Fe}_{3} \mathrm{O}_{4}\right)$, goethite $(\alpha-\mathrm{FeOOH})$, and lepidocrocite $(\gamma-\mathrm{FeOOH}) . J$ Geophys Res Solid Earth 90:3126-3144.

Murchie, S., Arvidson, R., Bedini, P., Beisser, K., Bibring, J.P., Bishop, J., Boldt, J., Cavender, P., Choo, T., Clancy, R.T., Darlington, E.H., Des Marais, D., Espiritu, R., Fort, D., Green, R., Guinness, E., Hayes, J., Hash, C., Heffernan, K., Hemmler, J., Heyler, G., Humm, D., Hutcheson, J., Izenberg, N., Lee, R., Lees, J., Lohr, D., Malaret, E., Martin, T., McGovern, J.A., McGuire, P., Morris, R., Mustard, J., Pelkey, S., Rhodes, E., Robinson, M., Roush, T., Schaefer, E., Seagrave, G., Seelos, F., Silverglate, P., Slavney, S., Smith, M., Shyong, W.-J., Strohbehn, K., Taylor, H., Thompson, P., Tossman, B., Wirzburger, M., and Wolff, M. (2007) Compact reconnaissance imaging spectrometer for Mars (CRISM) on Mars reconnaissance orbiter (MRO). J Geophys Res 112: E05S03.

Noe Dobrea, E.Z., Wray, J.J., Calef, F.J., Parker, T.J., and Murchie, S.L. (2012) Hydrated minerals on Endeavour Crater's rim and interior, and surrounding plains: new insights from CRISM data. Geophys Res Lett 39:L23201. 
Qi, H., Ku, T.-L., and Phillips, F.M. (1993) Evolutionary characteristics of lakes and palaeoclimatic undulation in the Qaidam Basin, China. Chin J Oceanol Limnol 11:34-45.

Rieder, R., Gellert, R., Brückner, J., Klingelhöfer, G., Dreibus, G., Yen, A., and Squyres, S.W. (2003) The new Athena alpha particle X-ray spectrometer for the Mars Exploration Rovers. J Geophys Res Planets 108:8066.

Robinson, M.S., Brylow, S.M., Tschimmel, M., Humm, D., Lawrence, S.J., Thomas, P.C., Denevi, B.W., BowmanCisneros, E., Zerr, J., Ravine, M.A., Caplinger, M.A., Ghaemi, F.T., Schaffner, J.A., Malin, M.C., Mahanti, P., Bartels, A., Anderson, J., Tran, T.N., Eliason, E.M., McEwen, A.S., Turtle, E., Jolliff, B.L., and Hiesinger, H. (2010) Lunar reconnaissance orbiter camera (LROC) instrument overview. Space Sci Rev 150:81-124.

Rull, F., Vegas, A., Sansano, A., and Sobron, P. (2011) Analysis of Arctic ices by remote Raman spectroscopy. Spectrochim Acta A Mol Biomol Spectrosc 80:148-155.

Ryerson, R.A., Morain, S.A., Henderson, F.M., Budge, A.M., Rencz, A.N., and Lewis, A.J. (1999) Manual of Remote Sensing, Remote Sensing for the Earth Sciences. Wiley, Hoboken, NJ.

Salisbury, J.W. and D'Aria, D.M. (1994) Emissivity of terrestrial materials in the $3-5[\mathrm{mu}] \mathrm{m}$ atmospheric window. Remote Sens Environ 47:345-361.

Salle, B., Lacour, J.L., Vors, E., Fichet, P., Maurice, S., Cremers, D.A., and Wiens, R.C. (2004) Laser-induced breakdown spectroscopy for Mars surface analysis: capabilities at stand-off distances and detection of chlorine and sulfur elements. Spectrochim Acta Part B At Spectrosc 59:1413-1422.

Sarrazin, P., Brunner, W., Blake, D., Gailhanou, M., Bish, D.L., Vaniman, D.T., Chipera, S.J., Ming, D.W., Steele, A., Midtkandal, I., Amundsen, H., and Peterson, R. (2008) Field studies of Mars analog materials using a portable XRD/XRF instrument. In Lunar and Planetary Institute Science Conference Abstracts, Houston, TX, p 2421.

Schmidt, R. (2003) Mars Express-ESA's first mission to planet Mars. Acta Astronaut 52:197-202.

Seelos, K.D., Arvidson, R.E., Jolliff, B.L., Chemtob, S.M., Morris, R.V., Ming, D.W., and Swayze, G.A. (2010) Silica in a Mars analog environment: Ka'u Desert, Kilauea Volcano, Hawaii. J Geophys Res Planets 115:E00D15.

Sobron, P. and Alpers, C.N. (2013) Raman spectroscopy of efflorescent sulfate salts from Iron Mountain Mine Superfund Site, California. Astrobiology 13:270-278.

Sobron, P., Lefebvre, C., Leveille, R., Koujelev, A., Haltigin, T., Du, H., Wang, A., Cabrol, N., Zacny, K., and Craft, J. (2013a) Geochemical profile of a layered outcrop in the Atacama analogue using laser-induced breakdown spectroscopy: implications for Curiosity investigations in Gale. Geophys Res Lett 40:1965-1970.

Sobron, P., Lopez-Reyes, G., and Wang, A. (2013b) Automated mineral identification in three Mars analogue sites using in situ NIR reflectance spectroscopy and linear spectral unmixing. In: Analog Sites for Mars Missions II: Past, Present and Future Missions to Mars, Washington, DC, p 4033.

Sobron, P., Sanz, A., Acosta, T., and Rull, F. (2009) A Raman spectral study of stream waters and efflorescent salts in Río Tinto, Spain. Spectrochim Acta A Mol Biomol Spectrosc 71: 1678-1682.

Sobron, P., Sobron, F., Sanz, A., and Rull, F. (2008) Raman signal processing software for automated identification of mineral phases and biosignatures on Mars. Appl Spectrosc 62: 364-370.
Sobron, P. and Wang, A. (2010) A planetary environment and analysis chamber equipped with multiple spectroscopic sensors. In Lunar and Planetary Institute Science Conference Abstracts, Houston, TX, p 1994.

Sobron, P. and Wang, A. (2011) Spectral data processing for LIBS quantitative elemental analysis of geological samples. In Lunar and Planetary Institute Science Conference Abstracts, Houston, TX, p 1640.

Sobron, P. and Wang, A. (2012) A planetary environment and analysis chamber (PEACh) for coordinated Raman-LIBS-IR measurements under planetary surface environmental conditions. J Raman Spectrosc 43:212-227.

Sobron, P. and Wang, A. (2017) Exploring planetary analogs with an ultracompact near-infrared reflectance instrument. In AGU Fall Meeting Abstracts, New Orleans, LA, p P41B2836.

Summons, R.E., Miller, K., Glavin, D.P., Eigenbrode, J.L., Freissinet, C., Martin, M.G., and Team, M. (2013) Organic carbon compounds detected by the SAM instrument suite on Curiosity: results of the first year of exploration at Gale Crater (Invited). In AGU Fall Meeting Abstracts, San Francisco, CA, 13:03.

Toulmin, P., Baird, A.K., Clark, B.C., Keil, K., Rose, H.J., Christian, R.P., Evans, P.H., and Kelliher, W. C. (1977) Geochemical and mineralogical interpretation of the Viking inorganic chemical results. J Geophys Res 82:46254634.

Underhill, C. (1979) Infrared and Raman spectroscopy of graphite-ferric chloride. Solid State Commun 29:769-774.

Vago, J., Gardini, B., Kminek, G., Baglioni, P., Gianfiglio, G., Santovincenzo, A., Bayón, S., and van Winnendael, M. (2006) ExoMars: Searching for Life on the Red Planet. In: ESA Bulletin 126, pp 17-23.

Vítek, P., Edwards, H.G.M., Jehlička, J., Ascaso, C., De Los Ríos, A., Valea, S., Jorge-Villar, S.E., Davila, A.F., and Wierzchos, J. (2010) Microbial colonization of halite from the hyper-arid Atacama Desert studied by Raman spectroscopy. Philos Trans A Math Phys Eng Sci 368:3205-3221.

Wang, A. (2013) WIR, a near IR reflectance spectrometer for in situ identification of hydrous salts, other $\mathrm{H}_{2} \mathrm{O} / \mathrm{OH}$-bearing species, and biomarkers. In Low Cost Planetary Mission Conference, Pasadena, CA, p 221.

Wang, A., Freeman, J.J., Chou, I.M., and Jolliff, B.L. (2011) Stability of Mg-sulfates at-10 degrees $\mathrm{C}$ and the rates of dehydration/rehydration processes under conditions relevant to Mars. J Geophys Res Planets 116:E12006.

Wang, A., Freeman, J.J., and Jolliff, B.L. (2009) Phase transition pathways of the hydrates of magnesium sulfate in the temperature range 50 degrees $\mathrm{C}$ to 5 degrees $\mathrm{C}$ : implication for sulfates on Mars. J Geophys Res Planets 114:E04010.

Wang, A., Freeman, J.J., and Jolliff, B.L. (2015) Understanding the Raman spectral features of phyllosilicates. J Raman Spectrosc 46:829-845.

Wang, A., Freeman, J.J., Sobron, P., and Lambert, J. (2010a) A miniaturized near infrared instrument for detecting $\mathrm{H}_{2} \mathrm{O} / \mathrm{OH}$, sulfates, carbonates and organic species during planetary surface explorations. In Lunar and Planetary Institute Science Conference Abstracts, Houston, TX, p 2018.

Wang, A., Sobron, P., Kong, F., Zheng, M., and Zhao, Y.S. (2018) DLT saline playa in an hyperarid region on Tibet Plateau-II: preservation of salts with high hydration degrees in subsurface. Astrobiology 18:XX:XX.

Wang, G., Hao, Z., Huang, Z., Chen, L., Li, X., Hu, C., and Liu, Y. (2010b) Raman spectroscopic analysis of a desert cyano- 
bacterium Nostoc sp. in response to UVB radiation. Astrobiology 10:783-788.

Warren-Rhodes, K., Weinstein, S., Piatek, J.L., Dohm, J., Hock, A., Minkley, E., Pane, D., Ernst, L.A., Fisher, G., Emani, S., Waggoner, A.S., Cabrol, N.A., Wettergreen, D.S., Grin, E., Coppin, P., Diaz, C., Moersch, J., Oril, G.G., Smith, T., Stubbs, K., Thomas, G., Wagner, M., Wyatt, M., and Ng Boyle, L. (2007) Robotic ecological mapping: habitats and the search for life in the Atacama Desert. J Geophys Res Biogeosci 112:G04S06.

Wiens, R., Maurice, S., Barraclough, B., Saccoccio, M., Barkley, W., Bell, J., III, Bender, S., Bernardin, J., Blaney, D., Blank, J., Bouyé, M., Bridges, N., Bultman, N., Caïs, P., Clanton, R.C., Clark, B., Clegg, S., Cousin, A., Cremers, D., Cros, A., DeFlores, L., Delapp, D., Dingler, R., D’Uston, C., Dyar, M.D., Elliott, T., Enemark, D., Fabre, C., Flores, M., Forni, O., Gasnault, O., Hale, T., Hays, C., Herkenhoff, K., Kan, E., Kirkland, L., Kouach, D., Landis, D., Langevin, Y., Lanza, N., LaRocca, F., Lasue, J., Latino, J., Limonadi, D., Lindensmith, C., Little, C., Mangold, N., Manhes, G., Mauchien, P., McKay, C., Miller, E., Mooney, J., Morris, R.V., Morrison, L., Nelson, T., Newsom, H., Ollila, A., Ott, M., Pares, L., Perez, R., Poitrasson, F., Provost, C., Reiter, J.W., Roberts, T., Romero, F., Sautter, V., Salazar, S., Simmonds, J.J., Stiglich, R., Storms, S., Striebig, N., Thocaven, J.-J., Trujillo, T., Ulibarri, M., Vaniman, D., Warner, N., Waterbury, R., Whitaker, R., Witt, J., and Wong-Swanson, B. (2012) The ChemCam instrument suite on the Mars Science Laboratory (MSL) rover: body unit and combined system tests. Space Sci Rev 170:167-227.

Williford, K.H., Farley, K.A., Stack, K.M., Allwood, A.C., Beaty, D., Beegle, L.W., Bhartia, R., Brown, A.J., de la Torre Juarez, M., Hamran, S.-E. and others. (2018) Chapter 11 - The NASA Mars 2020 Rover Mission and the Search for Extraterrestrial Life. In: From Habitability to Life on Mars, edited by N.A. Cabrol and E.A. Grins, Elsevier, New York, NY, pp 275-308.

Xia, W., Zhang, N., Yuan, X., Fan, L., and Zhang, B. (2001) Cenozoic Qaidam Basin, China: a stronger tectonic inversed, extensional rifted basin. Am Assoc Pet Geol Bull 85: $715-736$.

Xiao, L., Wang, J., Dang, Y., Cheng, Z., Huang, T., Zhao, J., Xu, Y., Huang, J., Xiao, Z., and Komatsu, G. (2017) A new terrestrial analogue site for Mars research: the Qaidam Basin, Tibetan Plateau (NW China). Earth Sci Rev 164:84-101.

Zheng, M. (1997) An Introduction to Saline Lakes on the Qinghai-Tibet Plateau. Kluwer Academic Publishers, Dordrecht, The Netherlands.

Zurek, R.W. and Smrekar, S.E. (2007) An overview of the Mars reconnaissance orbiter (MRO) science mission. J Geophys Res 112:E05S01.

Address correspondence to: Pablo Sobron SETI Institute

189 Bernardo Avenue Suite 200 Mountain View, CA 94043

E-mail: psobron@seti.org

Submitted 19 October 2017 Accepted 11 February 2018

$\begin{aligned} & \text { Abbreviations Used } \\ \text { ASTER } & =\text { advanced spaceborne thermal emission } \\ & \quad \text { and reflection radiometer } \\ \text { DLT } & =\text { Dalangtan } \\ \text { FLAASH } & =\text { fast line-of-sight atmospheric analysis } \\ & \quad \text { of spectral hypercubes } \\ \text { LIBS } & =\text { laser-induced breakdown spectroscopy } \\ \text { MNF } & =\text { minimum noise fraction } \\ \text { NIR } & =\text { near-infrared } \\ \text { PPI } & =\text { Pixel Purity Index } \\ \text { SAM } & =\text { Spectral Angle Mapper } \\ \text { SNR } & =\text { signal-to-noise ratio } \\ \text { SWIR } & =\text { shortwave infrared } \\ \text { TIR } & =\text { thermal infrared } \\ \text { UV } & =\text { ultraviolet } \\ \text { VNIR } & =\text { visible near-infrared } \\ \text { WIR } & =\text { water infrared } \\ \text { WUSTL } & =\text { Washington University in St. Louis } \\ \text { XLS } & =\text { Xiaoliangshan } \\ \text { XRD } & =\text { X-ray diffraction } \\ \text { XRF } & =\text { X-ray fluorescence }\end{aligned}$

